\title{
IDENTIFICAÇÃO DE MARCADORES MOLECULARES LIGADOS A GENE DE RESISTÊNCIA AO VÍRUS DO MOSAICO (PRSV-W) EM MELÃO (Cucumis melo L.)
}

\author{
ANA PAULA MATOSO TEIXEIRA
}

Dissertação apresentada à Escola Superior de Agricultura "Luiz de Queiroz",

Universidade de São Paulo, para obtenção do título de Mestre em

Agronomia, Área de Concentração:

Fitopatologia.

PIRACICABA

Estado de São Paulo - Brasil

Julho - 2004 


\title{
IDENTIFICAÇÃO DE MARCADORES MOLECULARES LIGADOS A GENE DE RESISTÊNCIA AO VÍRUS DO MOSAICO (PRSV-W) EM MELÃO (Cucumis melo L.)
}

\author{
ANA PAULA MATOSO TEIXEIRA
}

Engenheira Agrônoma

Orientador: Prof. Dr. LUIS EDUARDO ARANHA CAMARGO

Dissertação apresentada à Escola Superior de Agricultura "Luiz de Queiroz", Universidade de São Paulo, para obtenção do título de Mestre em Agronomia, Área de Concentração: Fitopatologia.

PIRACICABA

Estado de São Paulo - Brasil Junho - 2004 


\section{Dados Internacionais de Catalogação na Publicação (CIP) DIVISÃO DE BIBLIOTECA E DOCUMENTAÇÃO - ESALQ/USP}

Teixeira, Ana Paula Matoso

Identificação de marcadores moleculares ligados a gene de resistência ao vírus do mosaico (PRSV-W) em melão (Cucumis melo L.) / Ana Paula Matoso Teixeira. - -

Piracicaba, 2004 / Ana Paula Matoso Teixeira. -- Piracicaba, 2004.

50 p. : il.

Dissertação (mestrado) - - Escola Superior de Agricultura Luiz de Queiroz, 2004.

Bibliografia.

1. Marcador molecular 2. Melão 3. Mosaico (doença de planta) 4. Resistência genética vegetal 5 . Vírus de plantas I. Título

CDD 635.61

"Permitida a cópia total ou parcial deste documento, desde que citada a fonte - O autor" 
A minha família pelo carinho, incentivo e apoio constantes

Dedico 


\section{AGRADECIMENTOS}

Ao Prof. Dr. Luis Eduardo Aranha Camargo pela orientação, apoio, compreensão e dedicação durante estes anos.

Aos professores do Departamento de Fitopatologia da ESALQ/USP pela oportunidade de aprendizado, sugestões e auxílio durante a elaboração deste trabalho.

À empresa Sakata Seed Sudamerica por todo apoio estrutural e científico dispensado.

Aos meus pais Edi e Lisa e meus irmãos Pedro, Cátia e Rafa por todo carinho, apoio, compreensão e paciência.

Ao Marcelo pelo companheirismo, respeito, atenção e paciência.

Aos amigos Alessandra, Kátia, Rodrigo, Patrícia e Maria Teresa pelo auxílio técnico-científico durante todo o trabalho.

Aos colegas do Laboratório de Genética Molecular Daniela, Célia, Maria Teresa, Kátia, Viviane, Rodrigo, Patrícia, Alessandra, Paulo, Carol, Regina, Cláudia, Jorge, Maeli, Flávia, Alice, Giovana, Maria Cristina, Osmar, Camila, Marcelo, Alessandra Penha, Raphaelle, Ademir, Thayne, Julia, Mariana, Daniel, Sandra, Reinaldo, Emerson, Vanoli e Fátima pela ajuda e amizade. 
Aos colegas da Empresa Sakata, pela ajuda e companheirismo, Olga, Romulo e Robert.

A todos os colegas do curso de pós-graduação em Fitopatologia pela amizade e bons momentos vividos.

Aos funcionários do Departamento de Fitopatologia Heloisa, Fernanda, Rodolfo, Marina, Jeferson, Pedro, Sílvia, Marise e Edivaldo, por todo o auxílio.

A todos que direta ou indiretamente contribuíram para a execução deste trabalho.

À FAPESP pelo auxílio financeiro. 


\section{SUMÁRIO}

Página

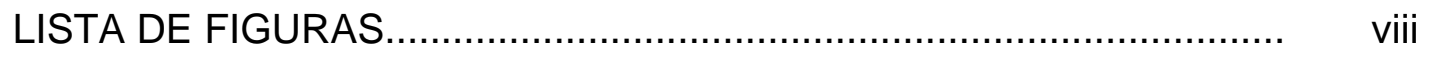

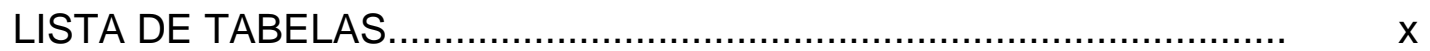

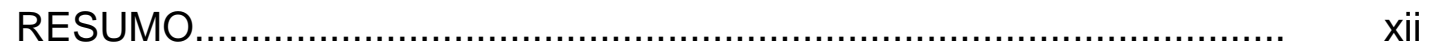

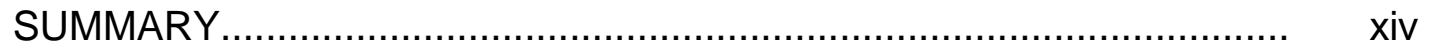

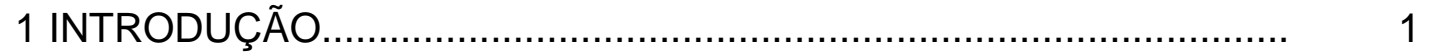

2 REVISÃO DE LITERATURA..................................................... 3

2.1 Origem e Importância econômica da cultura do melão..................... 3

2.2 Patossistema melão X PRSV-W................................................ 4

2.2.1 Distribuição geográfica e importância........................................ 4

2.2.2 Etiologia, sintomatologia e epidemiologia................................. 5

2.2.3 Controle e resistência genética........................................ 7

2.3 Retrocruzamento e linhagens quase-isogênicas............................. 8

2.4 Marcadores moleculares....................................................... 9

2.4.1 Marcadores moleculares AFLPs............................................ 10

2.4.2 Marcadores moleculares em melão.......................................... 11 
3 MATERIAL E MÉTODOS ................................................... 13

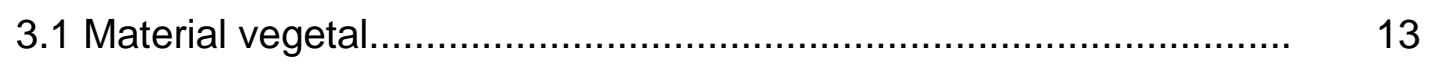

3.2 Avaliação da resistência de plantas da população RC1F1 a PRSVW.

3.3 Genotipagem das linhagens e população RC1F1 por meio de AFLP

3.3.1 Extração de DNA....................................................... 14

3.3.2 Reações de AFLP........................................................ 15

3.4 Utilização de marcadores AFLPs ligados a gene de resistência a PRSV-W em pepino.............................................................. 20

3.5 Análise dos resultados......................................................... 21

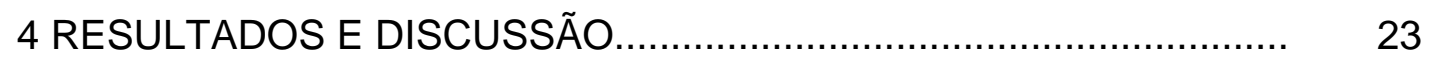

4.1 Avaliação da resistência de plantas da população RC1F1 a PRSVW.

4.2 Genotipagem das linhagens e população RC1F1 por meio de AFLP..

4.3 Análise de ligação entre marcadores ligados a gene de resistência a PRSV-W em pepino e gene de resistência a PRSV de melão...

4.4 Análise de ligação entre marcadores candidatos e gene de resistência a PRSV-W............................................................ 29

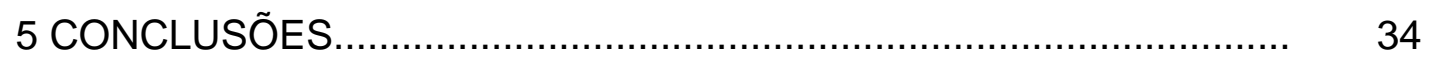

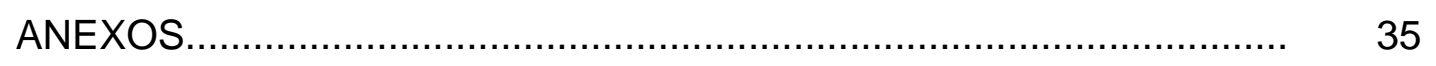

REFERÊNCIAS BIBLIOGRÁFICAS ............................................ 42 


\section{LISTA DE FIGURAS}

Página

1 A - plantas resistentes da população de retrocruzamento (P2XP1)XP1 com fortes sintomas de hipersensibilidade; B - plantas suscetíveis da mesma população com sintomas de mosaico causados pelo vírus PRSV-W.

2 Reações das linhagens parentais ao PRSV-W. Da esquerda para a direita vêem-se a linhagem P3 doadora do gene (LRD), a linhagem (P1) quase isogênica suscetível (LQI-S) e a linhagem (P2) quase isogênica resistente (LQI-R).

3 Gel de acrilamida onde aparece o polimorfismo EA270 indicado pelas setas. $\mathrm{LRD}=$ linhagem doadora do gene; LQI-R = linhagem quase isogênica resistente; LQI-S = linhagem quase isogênica suscetível; 5 - 42 = população segregante RC1F1 $(R=$ resistente; $S$ = suscetível; 0 = ausência do fragmento; $1=$ presença do fragmento)

4 Gel de acrilamida onde aparece o polimorfismo HF155 indicado pelas setas. LRD = linhagem doadora do gene; LQI-R = linhagem quase isogênica resistente; LQI-S = linhagem quase isogênica suscetível; 1-25 = população Segregante RC1F1 $(R=$ resistente; $S=$ suscetível; 0 = ausência do fragmento; 1 = presença do fragmento; $N$ = falha de amplificação)

5 Gel de acrilamida onde aparece o polimorfismo EK190 indicado 
pelas setas. LRD = linhagem doadora do gene; LQI-R = linhagem quase isogênica resistente; LQI-S = linhagem quase isogênica suscetível; 55-89 = população Segregante RC1F1 ( $R$ = resistente; S = suscetível; 0 = ausência do fragmento; 1 = presença do fragmento; $\mathrm{N}=$ falha de amplificação). 


\section{LISTA DE TABELAS}

Página

1 Seqüências dos adaptadores e dos iniciadores utilizados na análise genética das linhagens.

2 Resultados da avaliação da população RC1F1 à inoculação com PRSV-W e resultado do teste de $\chi^{2}$.

3 Número de plantas resistentes e suscetíveis com presença ou ausência dos fragmentos EA270 e HF155 na população RC1F1 avaliada quanto à resistência a PRSV-W. Números entre parênteses indicam os valores esperados no caso de segregação independente entre gene e marcador.

6 Número de plantas resistentes e suscetíveis com presença ou ausência do fragmento EK190 na população RC1F1 avaliada quanto à resistência a PRSV-W. Números entre parênteses indicam os valores esperados no caso de segregação independente entre gene e marcador.

4 Resultados da fenotipagem (Fen) e da genotipagem (Gen) da população segregante RC1F1 para 0 fragmento EA270. $\mathrm{R}=$ resistente, $\mathrm{S}=$ suscetível, $1=$ presença do fragmento e $0=$ =ausência do fragmento

5 Resultados da fenotipagem (Fen) e da genotipagem (Gen) da população segregante RC1F1 para o fragmento HF155. $\mathrm{R}=$ resistente, $\mathrm{S}=$ suscetível, $1=$ presença do fragmento e $0=$ ausência do fragmento. 
7 Resultados da fenotipagem (Fen) e da genotipagem (Gen) da população segregante RC1F1 para o fragmento EK190. $\mathrm{R}=$ resistente, $\mathrm{S}=$ suscetível, $1=$ presença do fragmento e $0=$ =ausência do fragmento...... 


\title{
IDENTIFICAÇÃO DE MARCADORES MOLECULARES LIGADOS A GENE DE RESISTÊNCIA AO VÍRUS DO MOSAICO (PRSV-W) EM MELÃO (Cucumis melo L)
}

\author{
Autora: ANA PAULA MATOSO TEIXEIRA
}

Orientador: Prof. Dr. LUIS EDUARDO ARANHA CAMARGO

\section{RESUMO}

\begin{abstract}
A importância da cultura do meloeiro é crescente no Brasil, sobretudo na região Nordeste, tanto pelo volume comercializado como por ser estabelecida geralmente em pequenas propriedades. Diversas enfermidades acometem esta cultura, destacando-se as viroses. Dentre estas, o mosaico, causado pelo Papaya ringspot virus - estirpe melancia (PRSV-W) é das mais importantes. Dentre as estratégias de controle desta doença, o emprego de cultivares resistentes apresenta-se como um método prático e eficiente. $\mathrm{O}$ objetivo deste trabalho foi identificar marcadores moleculares do tipo AFLP ligados ao gene $P r V^{1}$ de resistência a PRSV-W em melão que futuramente pudessem ser utilizados em seleção assistida por marcadores. Para isto, foram analisadas duas linhagens quase-isogênicas (LQI-R e LQI-S) do tipo Amarelo CAC contrastantes para resistência ao vírus e uma linhagem do tipo Charentais doadora do gene de resistência. A LQI resistente foi obtida através de cruzamento entre a linhagem doadora do gene (LRD) e a linhagem recorrente
\end{abstract}


(LQI-S), seguido de cinco retrocruzamentos de plantas resistentes com a linhagem recorrente. A porcentagem do genoma do parental recorrente recuperado na LQI-R foi de aproximadamente 98,44\%. Polimorfismos entre as linhagens resistentes e a suscetível foram considerados marcadores candidatos ligados ao gene de reistência $P r{ }^{1}$. Para análise de co-segregação entre gene e marcadores candidatos, foi utilizada uma população RC1F1, fenotipada para resistência a PRSV-W, obtida a partir do cruzamento entre as LQIs. Para cálculo da distância entre o gene e os marcadores foi utilizada fórmula de Kosambi para porcentagens de indivíduos recombinantes maiores que $1 \%$ e para porcentagens menores admitiu-se ser a distância em centiMorgans equivalente a esta porcentagem. A técnica AFLP em conjunto com a utilização de linhagens quase-isogênicas mostrou-se eficiente na detecção de marcadores moleculares em melão. Para digestão do DNA, foram utilizadas três combinações diferentes de enzimas de restrição (EcoRI/Msel, HindIII/Msel e Pstl/Msel), sendo avaliados perfis eletroforéticos gerados a partir da amplificação com 474 combinações diferentes de iniciadores. Aproximadamente 28.700 fragmentos foram analisados, sendo verificada diversidade genética de 8,6\% (2462 fragmentos polimórficos) entre as linhagens quase-isogênicas e a linhagem doadora Charentais. Apenas três fragmentos mostraram-se polimórficos na análise da população RC1F1, estando ligados ao gene de resistência a PRSV-W, de acordo com o teste de co-segregação. Os fragmentos EA270 e HF155 mostramse ligados entre si e estão localizados a uma distância aproximada de 40,9 cM do gene $P r v^{1}$, enquanto o fragmento EK190 mostrou-se ligado ao gene a uma distância de 0,526 cM. Pela sua proximidade ao gene $P^{1}{ }^{1}$, o marcador EK190 pode ser utilizado em programas de seleção assistida por marcadores moleculares visando o melhoramento de linhagens com resistência ao vírus PRSV-W. 


\title{
IDENTIFICATION OF MOLECULAR MARKERS LINKED TO A RESISTANCE GENE TO PRSV-W IN MELON (Cucumis melo L)
}

\author{
Author: ANA PAULA MATOSO TEIXEIRA \\ Adviser: Prof. Dr. LUIS EDUARDO ARANHA CAMARGO
}

\section{SUMMARY}

The growing importance of melon in Brazil is due to the increased production, especially in the Northern region, where crops are established in small properties. Several diseases affect melons. Among the viruses, the mosaic, caused by Papaya ringspot virus - type watermelon (PRSV-W) is the most important. The use of resistant cultivars is a practical and effective method of disease control. The objective of this work was to identify AFLP markers linked to the $P r V^{1}$ gene that confers resistance to PRSV-W, that in the future could be used in marker assisted selection. Two near isogenic lines (LQI-R and LQI-S) of the Amarelo CAC type that differ with respect to the presence of $\operatorname{PrV}^{1}$ and one Charentais type line donor of the resistance gene were analyzed. The resistant LQI was obtained through the crossing between the donor line (LRD) and the recurrent line (LQI-S), followed by five backcrosses between resistant plants and the recurrent line. The percentage of recurrent parental genome recovered in the LQI-R was approximately 98.44\%. Polymorphisms between resistant and 
susceptible lines were considered as candidate markers linked to the Prv ${ }^{1}$ resistance gene. An RC1F1 population obtained from a cross between the LQIs lines and screened for resistance to PRSV-W was used in co-segregation analyses. The distance between markers and resistance gene was calculated using the Kosambi equation for recombination fractions higher than $1 \%$. For lower values, the percentage of recombinants was considered equal to the distance in centiMorgans. The AFLP technique combined with the use of nearisogenic lines seemed to be efficient in detecting molecular markers in melon. DNA digestion was performed with three combinations of different enzymes (EcoRI/Msel, HindIII/Msel and Pstl/Msel), and electrophoretic profiles of fragments obtained from 474 combinations of different primers were evaluated. Approximately 28,700 fragments were analyzed. Genetic diversity was estimated as $8.6 \%(2,462$ polymorphic fragments) between near-isogenic lines and the donor Charentais line. Only three fragments were found to be polymorphic and linked to the resistance gene. The markers EA270 and HF155 are linked to each other and located $40.9 \mathrm{cM}$ of the Prv1 gene. The fragment EK190 is linked to the same gene with a distance of $0.526 \mathrm{cM}$. Because EK190 fragment is very close to the resistance gene, it is a suitable marker to be used in marker-assisted selection aiming to develop melon cultivars resistant to PRSV-W. 


\section{INTRODUÇÃO}

A importância da cultura do melão é crescente no Brasil, especialmente na região Nordeste. Isto se dá tanto pelo volume comercializado como por ser uma cultura de pequenas propriedades, em sua maioria de agricultura familiar. A cultura foi responsável por $17 \%$ da receita total gerada com exportações de frutas frescas pelo Brasil no ano de 2001, o equivalente a US\$ 37,778 milhões (FNP Consultoria \& Comércio, 2003).

Diversas enfermidades acometem a cultura, destacando-se entre elas as viroses. Há cinco principais vírus que afetam o meloeiro: CMV (Cucumber mosaic virus), WMV-1 (Watermelon mosaic virus-1), WMV-2 (Watermelon mosaic virus-2), ZYMV (Zucchini yellow mosaic virus) e PRSV-W (Papaya ringspot virus - watermelon). Destes, o último está presente em todas as regiões produtoras de cucurbitáceas, sendo em muitas delas o vírus de maior importância, dependendo do ano agrícola.

O uso de cultivares resistentes é o método mais eficiente de controle do PRSV-W em melão. Estas são obtidas através de melhoramento convencional, onde são realizados diversos cruzamentos e posterior fenotipagem dos indivíduos obtidos em cada um deles, por meio de inoculações em casa-de-vegetação. Este processo é trabalhoso pois exige disponibilidade constante de inóculo em quantidades consideráveis, principalmente por se tratar de um organismo biotrófico. Este é o principal motivo pelo qual o emprego da seleção assistida por marcadores moleculares (SAM) é importante para os programas de melhoramento, uma vez que minimiza a necessidade de fenotipagem. É importante ressaltar ainda que a SAM abre a possibilidade de 
seleção precoce, uma vez que esta pode ser feita em estádios de desenvolvimento iniciais em relação à seleção convencional.

Este trabalho visou identificar marcadores moleculares do tipo AFLP ligados a um gene dominante de resistência a PRSV-W, por meio da análise de duas linhagens quase isogênicas (LQI) contrastantes para presença do gene de resistência e uma terceira linhagem resistente, utilizada como doadora do gene. Para a confirmação da ligação entre marcadores e o gene de resistência, foi utilizada uma população segregante RC1F1, desenvolvida a partir de cruzamento entre as LQIs com posterior retrocruzamento do híbrido com a LQI suscetível. 


\section{REVISÃO DE LITERATURA}

\subsection{Origem e Importância econômica da cultura do melão}

O melão (Cucumis melo L.) é uma espécie originária da África e tem um amplo centro de diversidade, que se estende do Mar Mediterrâneo ao leste asiático (Diaz et al., 2003). Segundo Silberstein et al. (1999), as diferentes variedades são classificadas de acordo com suas características fenotípicas sendo agrestis, flexuosus, conomon, chito, dudaim, momordica, cantalupensis e inodorus alguns exemplos destas variedades. As duas últimas são as mais utilizadas comercialmente. A variedade cantalupensis tem como principais características a casca rendilhada ou com manchas longitudinais mais escuras, forte aroma, comportamento climatérico e sabor adocicado. Já a variedade inodorus possui casca de coloração mais uniforme, aroma ausente ou muito suave, comportamento não climatérico e maior durabilidade depois de colhido (Silberstein et al.,1999; Staub et al., 1997). A despeito da aparente elevada diversidade fenotípica, o polimorfismo em nível de DNA entre estes grupos de melões é relativamente baixo (Shattuck-Eidens et al., 1990; Neuhausen, 1992, citados por Wang et al., 1997). As plantas são diplóides (2n=24) e o tamanho total do genoma é de, aproximadamente, 9,0-10,0 $\times 10^{8} \mathrm{pb}$ (Arumuganathan \& Earle, 1991).

O melão foi responsável por $17 \%$ da receita total gerada com exportações de frutas frescas pelo Brasil no ano de 2001, equivalente a US\$ 37,778 milhões (FNP Consultoria \& Comércio, 2003). Neste ano, foram produzidas 98.690 toneladas numa área de 14.198 hectares. Praticamente todo melão exportado pelo Brasil é produzido no nordeste do país, onde o clima permite a produção do fruto durante o período de entressafra da Espanha 
(setembro a março) maior produtor europeu. Esta região foi responsável, em 2001, por aproximadamente 93\% da produção nacional e 80\% da área plantada, sendo seguida pela região Sudeste, que produziu um volume equivalente a pouco mais de $1,3 \%$ da produção nordestina (FNP Consultoria \& Comércio, 2003).

Além de sua importância na pauta de exportações do agribusiness, o cultivo do melão, sob o ponto de vista sócio-econômico, representa uma importante atividade geradora de empregos, sobretudo por ser desenvolvida quase que exclusivamente por pequenos produtores em áreas tipicamente de agricultura familiar.

\subsection{Patossistema melão X PRSV-W}

\subsubsection{Distribuição geográfica e importância}

Doenças viróticas são um dos fatores mais limitantes para cucurbitáceas em todo o mundo. Luis-Arteaga et al. (1998), por exemplo, relataram sua importância em plantios de melão na Espanha, um dos maiores produtores. Cerca de 20 espécies de vírus já foram observadas no mundo afetando cucurbitáceas. Destas, oito já foram relatadas no Brasil. Segundo Yuki et al. (2000), no estado de São Paulo já foi constatada a presença de Cucumber mosaic virus (CMV), Papaya ringspot virus - type W (PRSV-W), Squash mosaic virus (SqMV), Watermelon mosaic virus - 2 (WMV-2), Zucchini yellow mosaic virus (ZYMV) e Zucchini lethal chlorosis virus (ZLCV).

O PRSV-W é muito comum em países tropicais e subtropicais, sendo considerado como limitante para diversas cucurbitáceas, principalmente quando a infecção ocorre no início do ciclo (Zambolim \& Dusi, 1995; Luis-Arteaga et al., 1998). É o vírus de ocorrência mais freqüente e de maior importância econômica em cucurbitáceas no Brasil (Zambolim \& Dusi, 1995), estando presente em quase todas as áreas de produção. Segundo Giampan \& Rezende (2001), PRSV-W predomina nas principais espécies de cucurbitáceas cultivadas no 
Estado de São Paulo. Segundo Yuki et al. (2000), este é o principal vírus também nos Estados do Pará, Rio Grande do Norte, Mato Grosso, Minas Gerais, Ceará e Distrito Federal. Esta é uma das doenças mais destrutivas da cultura do melão, muito embora não haja estimativas de perdas.

A distribuição e a severidade da doença são variáveis entre anos em uma mesma área bem como entre áreas distintas, provavelmente devido a variações de condições ambientais que interferem nas taxas de reprodução dos vetores e na suscetibilidade das plantas. Outras fontes de variação são a presença de plantas daninhas hospedeiras do vetor e a proximidade de áreas com plantios infestados de cucurbitáceas (Grafton-Cardwell et al.,1996; Yuki et al., 2000; Luis-Arteaga et al., 1998).

\subsubsection{Etiologia, sintomatologia e epidemiologia}

Há evidências que o vírus PRSV se originou na região da Índia subcontinental (Índia/Sri Lanka) (Bateson et al., 2002). No entanto, Quiot-Douine et al. (1990) suportam a tese de que este vírus se originou em algum local entre o norte da África e a Índia. Este vírus é classificado em duas estirpes que possuem vírions que não podem ser diferenciados por testes sorológicos, mas que diferem quanto às espécies que infectam (Bateson et al., 2002). A estirpe PRSV-W distingue-se de PRSV-P (Papaya ringspot virus - estirpe papaya) pelo fato de quase exclusivamente só infectar cucurbitáceas, num total de, aproximadamente, 40 espécies pertencentes a 11 gêneros (Zambolim \& Dusi, 1995), enquanto a estirpe PRSV-P infecta Carica papaya e a maioria das cucurbitáceas. No entanto, apesar de a estirpe PRSV-P poder ser transmitida experimentalmente para cucurbitáceas, não é comumente encontrada em cucurbitáceas em campo (Gonsalves, 1998, citado por Bateson et al., 2002). De acordo com Bateson et al. (1994; 2002), a estirpe PRSV-P provavelmente evoluiu de PRSV-W, presumivelmente por mutação. Isto é indicado pela alta 
similaridade existente entre as seqüências dos genes da capa protéica das duas estirpes e pelo fato de, na Austrália, a estirpe PRSV-W ter sido relatada 20 anos antes de PRSV-P.

PRSV-W foi inicialmente classificado como sendo uma estirpe do vírus WMV-1 ("Watermelon mosaic virus-1"). Este vírus, porém, foi reclassificado com base em estudos sorológicos e de círculo de hospedeiras, passando a ser denominado como uma estirpe do vírus do mosaico do mamoeiro ("Papaya ringspot virus- type watermelon- PRSV-W"). Trata-se de um Potyvirus caracterizado por se apresentar como partículas flexuosas alongadas de aproximadamente $780 \mathrm{~nm}$ de comprimento, que causam sintomas citológicos conhecidos por inclusões citoplasmáticas do tipo "cata-vento".

Em estudos realizados com relação às espécies hospedeiras, observou-se transmissão de PRSV-W para Chenopodium spp., resultando no aparecimento de lesões locais (Kurozawa \& Pavan, 1997). Outros autores também identificaram as espécies Tridax procumbens L. (erva-de-touro), Cleome viscosa L., C. spinosa Jacq. (sete-marias), Malvaviscus arboreus Cav. (malva-de-colibri), Sida rhombifolia L. (guanxuma) e Sphaeralcea angustifolia (Cav.) G. Don, como hospedeiras alternativas (Sanches et al., 1998 e JimenézDíaz, 1996, citados por Giampan \& Rezende, 2001). No Brasil, espécies selvagens de cucurbitáceas ocorrem quase que em todas as regiões e durante praticamente todas as épocas (Yuki et al., 2000), podendo desta maneira servir de reservatório para o vírus.

Vinte e uma espécies de afídeos são capazes de transmitir, de maneira não persistente, este vírus. Apesar de Myzus persicae não ser considerada uma praga de cucurbitáceas, é o principal vetor no Brasil por ser o mais eficiente na transmissão do vírus (Giampan \& Rezende, 2001; Yuki, 1990). Estes autores verificaram também que Aphis gossypii, Toxoptera citricidus Kirk e Lipaphis erysimi Kltb também transmitem PRSV-W, porém com uma menor eficiência. Ainda não foi relatada a transmissão deste vírus por sementes.

O sintoma inicial de infecção por PRSV-W é o amarelecimento internerval. Mais tarde aparecem sintomas que incluem mosaico, bolhas, 
distorções e estreitamento na lâmina foliar, nanismo na planta, nódulos e descoloração em frutos (Zitter et al., 1996; Blancard et al., 1994; Kurozawa \& Pavan, 1997; Luis-Arteaga et al., 1998; Grafton-Cardwell et al., 1996). A infecção precoce leva à redução na formação de flores e ao aborto de frutos (Grafton-Cardwell et al., 1996; Luis-Arteaga et al., 1998).

\subsubsection{Controle e resistência genética}

Para o controle da doença podem ser adotadas práticas culturais que incluem pulverizações com óleo mineral e cobertura do solo com palha de arroz na tentativa de repelir os afídeos. Ainda devem ser evitadas áreas próximas a plantios de cucurbitáceas que tenham sido infectados (Yuki et al., 2000) e devem ser eliminadas plantas daninhas hospedeiras de vetores e do vírus, mesmo que as mesmas não apresentem sintomas de mosaico. A disseminação do vírus pode ser limitada através do controle de afídeos, mas este procedimento não é eficaz em estádios avançados da epidemia (Zitter et al., 1996; Blancard et al., 1994). Um método promissor para o controle desta virose em cucurbitáceas é o uso de estirpes premunizantes de PRSV-W, que impede que ocorram grandes perdas em campo quando da infecção por estirpes mais virulentas (Giampan \& Rezende, 2001). Outro método eficiente é o uso de cultivares resistentes (Grafton-Cardwell et al., 1996; Diaz et al., 2003). No entanto, Diaz et al. (2003), estudando potenciais fontes de resistência para viroses em melão, analisaram 253 acessos diferentes, incluindo espécies selvagens, cultivares tradicionais e acessos de bancos de germoplasma, e concluíram que as fontes de resistência a PRSV-W são extremamente limitadas.

A resistência a PRSV-W em melão é conferida pelos genes dominantes $P r v^{1}, P r v^{2}$ e Prv2, dependendo de sua fonte de origem: PI 180280, PI 180283 ou PI 124112, respectivamente (Pitrat, 2002; Pitrat, 1998; Pitrat \& Lecoq, 1983; Webb, 1979). O gene de resistência $P r V^{1}$ foi o primeiro a ser relatado, inicialmente como sendo gene de resistência ao vírus WMV-1 devido à 
incorreta classificação do vírus que só mais tarde foi reclassificado como PRSV$W$. Isto fez com que o gene fosse denominado inicialmente de $W M V$, sendo posteriormente renomeado. Assim como os genes $\mathrm{Pr}^{2}$ e Prv2, este gene também é dominante, sendo $P r v^{1}$ e $P r v^{2}$ alelos de um mesmo locus. Não se conhece relação alélica entre os mesmos e Prv2. Segundo Sowell \& Demski ${ }^{1}$, citados por Pitrat \& Lecoq (1983), a comparação das reações de hipersensibilidade dos acessos selvagens PI $180280\left(P r v^{1}\right)$ e PI $180283\left(P r v^{2}\right)$, indicou mecanismos de resistência similares entre os dois genes. Porém, Lecoq et al. (1982) relataram diferenças nos sintomas apresentados por linhagens contendo estes genes. Em alguns casos, e dependendo do isolado de vírus, a linhagem resistente apresenta como sintomas de hipersensibilidade, em caso de inoculação experimental, lesões locais, necrose do ponteiro e morte, ou, simplesmente, não apresenta nenhum sintoma. Plantas com ausência de qualquer um dos três genes de resistência apresentam sintomas típicos da doença como os já citados.

Diversos híbridos com resistência múltipla a doenças foram obtidos e introduzidos comercialmente no mercado brasileiro nos últimos anos, destacando-se as séries AF-682 (1995), AF-1805 (1999) e AF-1814 (1999), obtidos pela empresa Sakata Seeds Sudamerica. São todos do tipo Amarelo e apresentam resistência à raça 1 de Podosphaera xanthii e a PRSV-W. Estes híbridos foram obtidos mediante métodos convencionais de melhoramento, baseados na observação do fenótipo das plantas selecionadas após inoculação com os patógenos.

\subsection{Retrocruzamento e linhagens quase-isogênicas}

Retrocruzamento é um método utilizado quando se deseja transferir uma característica, geralmente sob controle monogênico, para uma linhagem de

\footnotetext{
${ }^{1}$ Sowell \& Demski, 1981
} 
boas características agronômicas. Como o nome sugere, o método faz uso de uma série de retrocruzamentos a partir do cruzamento entre uma variedade doadora do gene e a linhagem a ser melhorada (recorrente). Os híbridos obtidos após cada cruzamento são selecionados para o gene em questão e usados como genitores em novo cruzamento com a linhagem recorrente. Segundo Allard (1960), ao final dos ciclos de retrocruzamento, os genes transferidos, diferentemente dos demais, encontram-se em heterozigose, sendo necessário ainda que se realize autofecundação para que se estabeleça a homozigose. Segundo Young \& Tanksley (1989), a técnica permite remover genes do parental doador não ligados ao gene de interesse, de maneira que, após oito retrocruzamentos, espera-se que menos de 0,2\% do total de regiões genômicas não ligadas ao gene de interesse e provenientes da linhagem doadora permaneçam na linhagem melhorada. Segundo os mesmos autores, após 20 ciclos de retrocruzamento, pequenas regiões de até $5 \mathrm{cM}$ em cada direção a partir do gene podem ainda persistir ligadas ao gene de interesse. Devido a isto, a análise comparativa de linhagens quase isogênicas é uma das técnicas mais eficazes para identificar marcadores ligados a genes de resistência, pois polimorfismos identificados entre as mesmas possuem maior possibilidade de estarem ligados ao gene em estudo (Muehlbauer et al., 1988; Young et al. 1988).

\subsection{Marcadores moleculares}

Marcadores moleculares são polimorfismos na seqüência nucleotídica do DNA existentes entre indivíduos. Quando localizados próximos a genes de interesse (ligação gênica), a presença de tais polimorfismos pode ser utilizada para inferir sobre a presença do gene devido ao fenômeno de co-segregação.

Por identificarem mesmo que indiretamente o genótipo desejado, marcadores moleculares ligados a genes de importância agronômica cujos fenótipos sejam de difícil avaliação permitem acelerar o processo de seleção 
(Daryono \& Natsuaki, 2002; Oliver et al., 2001; Wang et al., 2000). Isto porque, além de possibilitarem a redução das operações relacionadas a fenotipagem e manutenção de isolados em hospedeiros vivos no caso de parasitas obrigatórios, marcadores moleculares não são influenciados por condições ambientais, como pode ocorrer com a fenotipagem feita de maneira convencional.

De fato, nos últimos anos, a seleção assistida por marcadores (SAM) tornou-se uma ferramenta utilizada na rotina da seleção indireta de genótipos, especialmente para seleção de indivíduos resistentes a uma determinada doença (Paterson ${ }^{2}$ e Smith \& Beavis ${ }^{3}$, citados por Wang et al., 2000). Por exemplo, marcadores ligados a gene de resistência a Fusarium oxysporum f.sp. melonis identificados em melão por Zheng et al. (1999) hoje são utilizados em seleção assistida.

\subsubsection{Marcadores moleculares AFLPs}

Marcadores AFLPs (Amplified Fragment Length Polymorphism ou polimorfismo de comprimento de fragmentos amplificados) envolvem digestão do DNA genômico com combinações de enzimas de restrição. Usualmente, estas combinações são formadas por uma enzima de corte freqüente, ou seja, que cliva o DNA numa seqüência de 4 bases nucleotídicas, e uma enzima de corte raro, ou seja, com sítio de restrição formado por seis bases. A enzima de corte freqüente mais comumente empregada é a Mse I. Entre as enzimas de corte raro, as mais usuais são EcoR I, Pst I e Hind III (Ferreira \& Grattapaglia, 1998). Após a clivagem, adaptadores são ligados às extremidades coesivas dos fragmentos de DNA. Em seguida, é realizada amplificação dos fragmentos, utilizando-se para isto iniciadores que possuem um nucleotídeo arbitrário na

\footnotetext{
${ }^{2}$ Paterson, 1996

${ }^{3}$ Smith \& Beavis, 1996
} 
extremidade 3'. Após esta etapa, procede-se nova amplificação com iniciadores contendo mais um ou dois nucleotídeos além do nucleotídeo arbitrário da amplificação anterior. A resolução dos fragmentos é então realizada em gel de acrilamida.

Esta técnica combina a resolução e o poder de amostragem da digestão com enzimas de restrição com a velocidade e praticidade de detecção dos polimorfismos via PCR (reação em cadeia da polimerase), tendo como grande vantagem a possibilidade de se obter, ao final do processo, grande número de fragmentos amplificados, 50 a 100 por reação, segundo Vos et al. (1995). A técnica de AFLP tem sido utilizada em estudos de diversas naturezas. Por exemplo, para construção de mapas genéticos em milho (Castiglioli et al., 1999), melão (Wang et al., 1997; Oliver et al., 2001) e batata (van ECK et al., 1995). A técnica ainda tem sido usada para identificação de marcadores ligados a genes de interesse agronômico, como feito com pepino por Park et al. (2000) e com arroz por Nandi et al. (1997).

Comparando as técnicas de AFLP, RAPD e RFLP, Garcia-Mas et al. (2000) e Park et al. (2000), concluíram ser a técnica de AFLP a de maior eficiência na detecção de polimorfismos em melão, tanto pelo número de polimorfismos que permite analisar quanto pela alta resolução, uma vez que a eletroforese em gel de acrilamida permite que sejam separados fragmentos com diferenças em tamanho de um ou poucos nucleotídeos. Resultados semelhantes também foram obtidos por Wang et al. (1997) quando construíram um mapa genético de melão baseado em resultados de AFLP.

\subsubsection{Marcadores moleculares em melão}

A variabilidade genética em melão tem sido estudada utilizando-se marcadores bioquímicos ou marcadores moleculares, como, por exemplo, RFLP (Restriction Fragment Length Polymorphisms) e RAPD (Random Amplified 
Polymorphic DNA) (Guis, 1998). Porém, até recentemente, poucas eram as informações publicadas sobre mapas genéticos e identificação de marcadores moleculares associados a genes de interesse econômico na espécie.

Wechter \& Dean (1998), a partir de marcadores RAPD, desenvolveram dois marcadores SCAR (Sequence Characterized Amplified Regions) ligados ao gene Fom-2 que confere resistência à raça 1 de Fusarium oxysporum f. sp. melonis. Zhen et al. (1999), a partir de marcadores RAPD, desenvolveram um marcador CAPS (Cleaved Amplified Polymorphic Sequence) e RFLP (Restriction Fragment Length Polymorphism) ligados ao mesmo gene. Recentemente, Karsies et al. (2000) encontraram dois marcadores RAPD e dois marcadores AFLP ligados ao gene Fom-1 que confere resistência às raças 0 e 2 de Fusarium oxysporum f. sp. melonis. Danin-Poleg et al. (2000), identificaram um marcador microssatélite proximamente ligado ao gene $Z y m-1$, que confere resistência ao vírus ZYMV (Zucchini yellow mosaic virus) em melão. Um outro microssatélite mostrou-se ligado a outro loco envolvido na resistência a este vírus. Os mesmos autores encontraram ainda quatro marcadores RAPD ligados a gene de resistência a CMV, sendo que dois deles foram mapeados em diferentes grupos de ligação e um deles gerou um marcador SCAR.

Pitrat (1991), estudando marcadores moleculares em melão, estabeleceu 8 grupos de ligação, concluindo haver ligação entre os genes Fom1, que confere resistência às raças 0 e 2 de Fusarium oxysporum f.sp. melonis, $P r v^{1}$, que confere resistência ao vírus PRSV-W e o gene $y v-X$, responsável por deficiência na produção de clorofila. A ordem mais provável de localização destes no genoma seria $y v-X-F o m-1-P r v^{1}$ e as prováveis distâncias entre os mesmos seriam de $33 \mathrm{cM}$ entre $y v-X$ e Fom-1 e de $32 \mathrm{cM}$ entre Fom-1 e Prv'. 


\section{MATERIAL E MÉTODOS}

\subsection{Material vegetal}

Foram utilizadas duas linhagens quase isogênicas do tipo Amarelo CAC pertencente à variedade inodorus: AF-426 (P1) e AF-2196 (P2). Estas são contrastantes para presença de $\mathrm{PrV}^{1}$, alelo dominante de resistência a PRSV-W. A linhagem resistente AF-2196, ou linhagem convertida, foi obtida pela empresa Sakata Seed Sudamerica através de cruzamento entre a linhagem suscetível recorrente AF-426 (Amarelo CAC) e uma linhagem doadora resistente AF-125 (P3), do tipo Charentais (variedade cantalupensis). Este cruzamento foi sucedido por cinco retrocruzamentos com a linhagem suscetível recorrente AF426 usando híbridos resistentes a PRSV-W. Após o quinto retrocruzamento, realizou-se autofecundação de indivíduos resistentes a fim de se estabelecer a homozigose para o gene de resistência.

O estudo de ligação entre marcadores candidatos e gene de resistência foi realizado utilizando-se uma população RC1F1 oriunda do retrocruzamento $\mathrm{P} 1 \times(\mathrm{P} 1 \times \mathrm{P} 2)$, desenvolvida pela empresa Sakata Seed Sudamerica.

\subsection{Avaliação da resistência de plantas da população RC1F1 a PRSV-W}

A avaliação da resistência das plantas da população RC1F1 a PRSVW foi feita com base em ensaio conduzido em casa-de-vegetação, na Estação Experimental de Bragança Paulista da empresa Sakata Seed Sudamerica, no 
período de junho-julho de 2003. Aproximadamente 200 plantas foram avaliadas quanto à reação ao patógeno. Como controle, foi feita inoculação em 10 indivíduos de cada linhagem parental (AF-426, AF-2196 e AF-125).

Como inóculo, utilizou-se 0 isolado PRSV-WIAGF, previamente caracterizado por sorologia via teste ELISA e mantido em plantas de abobrinha cv. Caserta. As plantas foram inoculadas aos doze dias após a semeadura, de maneira manual, esfregando-se um chumaço de algodão embebido em solução de inóculo sobre as folhas previamente polvilhadas com carborundum 600 mesh. A solução de inóculo foi preparada a partir da maceração de folhas infectadas de abobrinha Caserta em solução tampão contendo $\mathrm{Na}_{2} \mathrm{HPO}_{4}(8,6$ $\mathrm{g} / \mathrm{l})$ e $\mathrm{Na}_{2} \mathrm{SO}_{3}(5,0 \mathrm{~g} / \mathrm{l})$, com pH ajustado a 7,0 com solução $\mathrm{KH}_{2} \mathrm{PO}_{4}(27,2 \mathrm{~g} / \mathrm{l})$. Após a inoculação, o carborundum foi lavado com água. Uma nova inoculação foi realizada dois dias após, seguindo o mesmo protocolo. Folhas de cada uma das plantas foram coletadas cinco dias após a segunda inoculação, para posterior extração de DNA.

Os sintomas foram avaliados três semanas após a segunda inoculação mediante inspeção visual efetuada por três avaliadores. Foram consideradas suscetíveis plantas com sintomas evidentes de mosaico, bolhas ou distorções foliares e resistentes as que não apresentavam mosaico ou que apresentavam sinais de hipersensibilidade, caracterizados por pontuações necróticas.

\subsection{Genotipagem das linhagens e população RC1F1 por meio de AFLP}

\subsubsection{Extração de DNA}

A extração de DNA foi realizada macerando-se aproximadamente 0,3g de folhas congeladas em nitrogênio líquido em tubos "eppendorf" de 1,5 ml, com posterior incubação com $700 \mu$ de solução CTAB $(0,7 \mathrm{M} \mathrm{NaCl}, 1 \%$ CTAB, $50 \mathrm{mM}$ Tris pH8,0, 10mM EDTA, 0,1\% 2-mercaptoetanol), a $65^{\circ} \mathrm{C}$ por 60 
minutos, agitando-se delicadamente os tubos a cada 10 minutos. A seguir, foram adicionados $600 \mu$ por tubo de solução clorofórmio:álcool isoamílico (24:1), seguindo-se centrifugação por 5 minutos a 14.000rpm. O sobrenadante foi retirado, acrescentado de $600 \mu \mathrm{l}$ de CIA (24:1) e submetido a nova centrifugação. Desta vez, ao sobrenadante foram acrescentados $500 \mu \mathrm{l}$ de etanol, mantendo-se os tubos por 30 minutos a $-20^{\circ} \mathrm{C}$. Após este período, os tubos foram centrifugados a $14.000 \mathrm{rpm}$ por 5 minutos, ocorrendo assim a precipitação do DNA. O "pellet" foi lavado com etanol 75\% por cinco minutos, depois com etanol 90\% e a seguir com etanol absoluto por mais cinco minutos. Em seguida, o DNA foi seco e ressuspendido em $50 \mu$ de água estéril. Para eliminação do RNA, foi realizada digestão a temperatura ambiente por 12 horas com $2 \mu \mathrm{l}$ de RNase 1mg/ml (Gibco) (Hoisington et al., 1994).

\subsubsection{Reações de AFLP}

O protocolo utilizado para as reações de AFLP foi adaptado de S. Hazen e R. W. Ward (http://www.msu.edu/user/hazensam/aflp/AFLPprotocolo IMSU.html) e de Vos et al. (1995). O DNA genômico foi digerido com duas enzimas de restrição, uma de corte freqüente, isto é, com sítio de restrição de 4 pares de base, e outra de corte raro, ou seja, com sítio de restrição formado por 6 pares de base. Foram testadas três combinações de enzimas: EcoR I/Mse I, Pst I/Mse I e Hind III/Mse I.

As reações de digestão do DNA com as combinações EcoR I/Mse I e Hind III/Mse I foram compostas por $5 \mu$ de tampão OnePhorAll 10X (OPA; Amersham), 0,5 $\mu$ l de BSA (10 $\mu \mathrm{g} / \mu \mathrm{l}$; New England), $3 \mu \mathrm{l}$ de DNA (50-200ng/ $\mu \mathrm{l}) \mathrm{e}$ 5 unidades de cada uma das enzimas (EcoR I: 10unidades/ $\mu$; Gibco e Mse I: 10 unidades/ $\mu$ l; New England Biolabs; Hind III: 18unidades/ $\mu$; Pharmacia) em um volume final de $50 \mu \mathrm{l}$. A reação foi incubada a $37^{\circ} \mathrm{C}$ por 3 horas. Posteriormente, as enzimas foram desnaturadas a $70^{\circ} \mathrm{C}$ por 15 minutos. Para a combinação 
Pstl/Mse I (Pst I: 10 unidades/ $\mu$; Invitrogen), as reações foram semelhantes, exceto que o tampão utilizado neste caso foi React 1 10X (Invitrogen).

Os adaptadores EcoR I, Pst I e Hind III (Tabela 1) foram diluídos a 5pM em solução 0,5X de tampão One Phor All 10X (OPA; Amersham). Os adaptadores Mse I (Tabela 1) foram diluídos a 50pM em solução 0,5X de tampão One Phor All 10X (OPA; Amersham). A hibridização das fitas de adaptadores foi realizada em termociclador modelo PTC-100 (MJ Research), por 10 minutos a $65^{\circ} \mathrm{C}, 10$ minutos a $37^{\circ} \mathrm{C}$ e 10 minutos a $25^{\circ} \mathrm{C}$. Após o preparo, os adaptadores foram acondicionados $\mathrm{a}-20^{\circ} \mathrm{C}$.

Os adaptadores foram ligados aos fragmentos de DNA em uma reação contendo $1 \mu$ l de tampão da enzima T4 DNA ligase (10X), $1 \mu$ le cada um dos adaptadores (5 ou 50 pM), 0,33 $\mu$ de T4 DNA ligase (3 unidades/ $\mu$; Promega), 6,67 $\mu$ l de água e 50 $\mu$ l de DNA digerido (150 a 600 ng). A ligação foi realizada a $22^{\circ} \mathrm{C}$ por três horas, com agitação dos tubos a intervalos de 40 minutos.

Os fragmentos de DNA foram amplificados em duas reações. Uma chamada de pré-amplificação e outra de amplificação seletiva. As reações de pré-amplificação foram efetuadas utilizando-se primers com seqüências complementares a cada um dos adaptadores mais um nucleotídeo seletivo na extremidade 3' (Tabela 1). Os iniciadores EcoR I utilizados nas reações de préamplificação são representados por $\mathrm{E}+\mathrm{N}$, sendo $\mathrm{N}$ o nucleotídeo seletivo. Já os iniciadores Mse I, Hind III e Pst I são representados por $\mathrm{M}+\mathrm{N}, \mathrm{H}+\mathrm{N}$ e $\mathrm{P}+\mathrm{N}$, respectivamente.

As reações de pré-amplificação foram compostas por $1 \mu$ de cada um dos iniciadores $(25 \mathrm{ng} / \mu \mathrm{l}), 0,8 \mu \mathrm{l}$ de dNTPs 10mM (Promega), $2 \mu \mathrm{l}$ de tampão (10X) da enzima Taq DNA polimerase (Promega), 1,2 $\mu \mathrm{l}$ de $\mathrm{MgCl}_{2}(25 \mathrm{mM}), 0,6 \mu \mathrm{l}$ de Taq DNA polimerase (5 unidades/ $\mu$ l; Promega), $2 \mu$ de DNA digerido e ligado em volume final de $20 \mu$ l. As reações de pré-amplificação foram iniciadas por um ciclo de desnaturação a $94^{\circ} \mathrm{C}$ por 2 minutos, seguido de 26 ciclos compostos de $94^{\circ} \mathrm{C}$ por 1 minuto, $56^{\circ} \mathrm{C}$ por 1 minuto e $72^{\circ} \mathrm{C}$ por 1 minuto, havendo um ciclo de 
extensão final a $72^{\circ} \mathrm{C}$ por 5 minutos. Ao produto da reação foram acrescentados $80 \mu \mathrm{l}$ de água MilliQ estéril. O produto desta reação foi armazenado a $-20^{\circ} \mathrm{C}$.

Tabela 1. Seqüências dos adaptadores e dos iniciadores utilizados na análise genética das linhagens

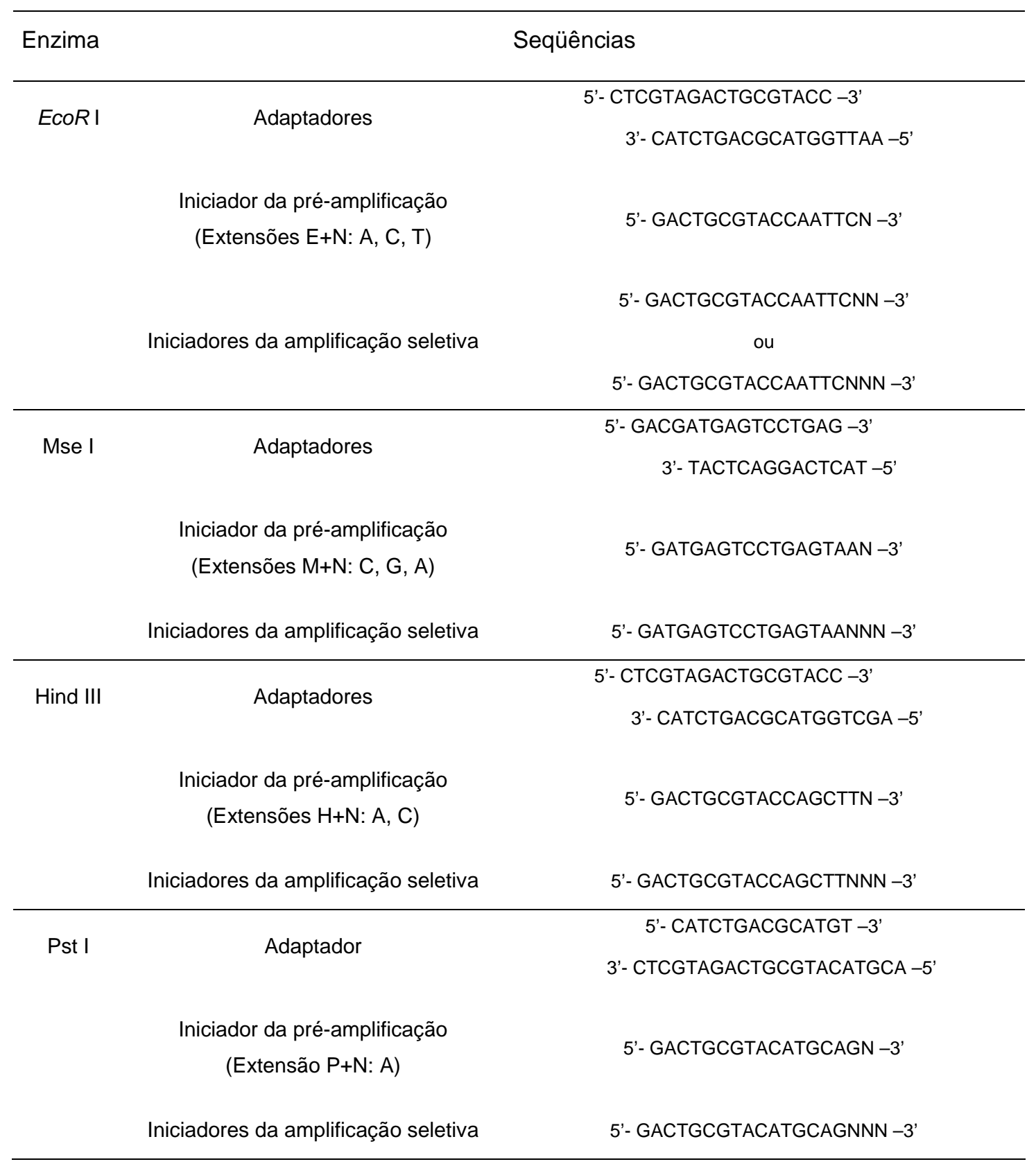


Por fim, foram realizadas reações de amplificação seletiva com primers com seqüências contendo 1 ou 2 nucleotídeos a mais na extremidade 3', além do já constante nos primers da reação de pré-amplificação, denominando-se estes primers agora de $E+N N$ ou E+NNN, P+NNN, H+NNN e $\mathrm{M}+\mathrm{NNN}$, sendo $\mathrm{N}$ uma representação dos nucleotídeos seletivos (Tabela 1).

As reações de amplificação seletiva foram compostas de $1,2 \mu l$ de cada iniciador $(25 \mathrm{ng} / \mu \mathrm{l}), 0,4 \mu \mathrm{l}$ de dNTPs 10mM (Promega), $2 \mu \mathrm{l}$ de tampão 10X

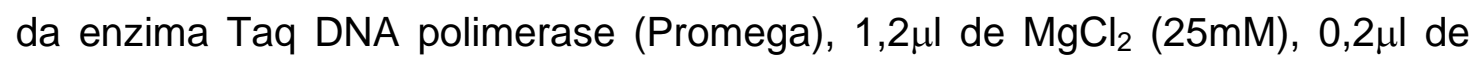

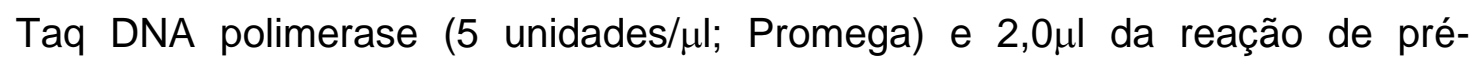
amplificação diluída, em volume final de $20 \mu \mathrm{l}$. O programa para amplificação foi composto por uma etapa inicial de desnaturação a $94^{\circ} \mathrm{C}$ por 2 minutos, passando a seguir por 12 ciclos formados por $94^{\circ} \mathrm{C}$ por 30 segundos, $65^{\circ} \mathrm{C}$ por 30 segundos e $72^{\circ} \mathrm{C}$ por 30 segundos. Após isto, foram realizados 23 ciclos compostos de $94^{\circ} \mathrm{C}$ por 30 segundos, $56^{\circ} \mathrm{C}$ por 30 segundos e $72^{\circ} \mathrm{C}$ por 30 segundos, havendo um ciclo de extensão final a $72^{\circ} \mathrm{C}$ por 5 minutos.

As amostras foram submetidas a eletroforese em gel de poliacrilamida $6 \%$ de $0,5 \mathrm{~mm}$ de espessura com utilização de sistema "Sequi-gen GT" (BioRad) de $38 \times 50 \mathrm{~cm}$ e pente de 50 dentes. Para o preparo de solução matriz foram utilizados $420 \mathrm{~g}$ de uréia, $3 \mathrm{~g}$ de bisacrilamida e $60 \mathrm{~g}$ de acrilamida, diluídos em TBE1X até completar 1 litro. Esta solução matriz foi filtrada a vácuo e armazenada em frascos envoltos em papel alumínio em refrigerador.

As placas utilizadas na montagem do gel foram cuidadosamente limpas utilizando-se etanol 95\%. Na placa maior foram aplicados $1,5 \mathrm{ml}$ de Repel (Amersham) deixando agir por 5 minutos e sendo retirado o excesso com álcool 95\%. Para o tratamento da placa menor (aderente) foram misturados em tubo eppendorf de 1,5 ml, $1 \mathrm{ml}$ de álcool 95\%, $5 \mu \mathrm{l}$ de Bind Silane (Amersham) e $5 \mu \mathrm{l}$ de ácido acético glacial. O produto foi aplicado à placa e seu excesso removido cinco minutos depois com álcool 95\%.

Para o preparo do gel foram utilizados $120 \mathrm{ml}$ da solução matriz, $120 \mu \mathrm{l}$ de TEMED (Promega) e $800 \mu \mathrm{l}$ de persulfato de amônio 10\% (Promega). 
Após a polimerização, foi realizada "pré-corrida", à potência constante de 80W por 1 hora, em cuba contendo TBE 1X na parte superior e solução de acetato de sódio $0,5 \mathrm{M}$ preparada em TBE $1 \mathrm{X}$ na parte inferior. A temperatura máxima para a eletroforese foi de $50^{\circ} \mathrm{C}$.

Aos produtos obtidos nas reações de amplificação seletiva foram adicionados $8 \mu \mathrm{l}$ de tampão de carregamento (10ml de formamida, $200 \mu \mathrm{l}$ de EDTA 0,5M pH8,0, $10 \mathrm{mg}$ de azul de bromofenol e $10 \mathrm{mg}$ de xilene cianol). A seguir, foi realizada desnaturação do produto de PCR por 5 minutos a $94^{\circ} \mathrm{C}$ imediatamente antes de ser realizada a eletroforese. Após a desnaturação, $15 \mu \mathrm{l}$ do produto de PCR já desnaturado foram aplicados em cada poço do gel. A eletroforese foi efetuada sob as mesmas condições da "pré-corrida", por período de 3,5 horas. Em todos os géis, aplicou-se marcador de peso molecular 50pb (Promega) preparado na proporção 1:16:8 de marcador, água milliQ e tampão de carregamento, respectivamente. O marcador foi desnaturado nas mesmas condições dos produtos de PCR.

A revelação dos géis foi realizada segundo protocolo adaptado de Creste et al. (2001). Os géis foram fixados em 2 litros de solução 1\% de ácido acético glacial e 10\% álcool etílico durante 10 minutos sob agitação constante. Após este período, procedeu-se lavagem por 1 minuto em 2 litros de água destilada sob agitação, sendo a seguir efetuada uma etapa de pré-tratamento por 2' 40" em ácido nítrico 1,5\%, lavando-se como anteriormente. A seguir, os géis foram tratados com solução de nitrato de prata a 0,2\%, sob agitação, por 20 minutos, passando posteriormente por 2 novas lavagens em 2 litros de água, desta vez sendo cada lavagem realizada por 30 segundos. Os fragmentos AFLPs foram revelados após incubação em solução gelada contendo $30 \mathrm{~g} / \mathrm{l}$ de carbonato de sódio mais $600 \mu \mathrm{l} / \mathrm{l}$ de formaldeído 37\%. Esta fase foi realizada em duas etapas com 1 litro de solução cada. A primeira etapa estendeu-se até que fosse possível perceber a presença de fragmentos amplificados no gel. A solução foi então trocada e a revelação continuou a ser realizada até que fosse obtida uma boa visualização dos fragmentos. Após esta etapa, os géis foram fixados em solução de ácido acético a 5\% por 5 minutos, sob agitação. 
Posteriormente, foi realizada uma última lavagem por um minuto com água destilada. Após este processo, os géis foram secos à temperatura ambiente por no mínimo doze horas.

A análise dos géis se deu colocando-os sobre transiluminador de luz branca, tendo sido registrados: a) o número total de fragmentos obtidos com cada combinação de primers por linhagem; b) o número total de fragmentos polimórficos entre a linhagem doadora e as linhagens quase isogênicas; e c) a presença de fragmentos polimórficos entre as linhagens resistentes e a quase isogênica suscetível.

Para os casos de polimorfismos, o tamanho dos fragmentos foi estimado por comparação com padrão de peso molecular de 50pb (Promega). Cada primer foi identificado por uma letra e os polimorfismos obtidos receberam denominação que consistiu das letras de cada um dos primers seguidas pelo tamanho do fragmento polimórfico em pares de base (pb). Por exemplo, um polimorfismo de 190pb obtido com a utilização dos primers $E$ e K, foi denominado EK190.

\subsection{Utilização de marcadores AFLPs ligados a gene de resistência a PRSV- W em pepino}

Trabalho desenvolvido por Park et al. (2000) relatou a ocorrência de marcadores AFLP próximos ao gene de resistência a PRSV-W em pepino (Cucumis sativus). Uma vez que melão e pepino são espécies do mesmo gênero, tentou-se a utilização destas mesmas combinações de primers para mapeamento do gene de resistência em melão.

As combinações testadas foram $M+C A A / E+C A, M+C A T / E+C A$ e $M+C A T / E+A T$ (Tabela 1), sendo todas as condições de amplificação, eletroforese e coloração do gel mantidas de acordo com o já citado. 


\subsection{Análise dos resultados}

Com relação à análise de géis, fragmentos observados nas linhagens resistentes AF125 (P3) e AF2196 (P2) e ausentes na linhagem suscetível AF3198 (P1) ou presentes na suscetível e ausentes nas resistentes foram considerados como marcadores potencialmente ligados ao gene de resistência (marcadores candidatos). Estes marcadores foram novamente amplificados com a finalidade de se confirmar os polimorfismos. Em caso positivo, foram feitas reações de amplificação com os indivíduos da população RC1F1 fenotipados para PRSV-W visando a observação de co-segregação entre marcador e gene.

Para análise dos dados da fenotipagem da população RC1F1 para resistência a PRSV-W, o teste $\chi^{2}$ foi empregado com a finalidade de verificar se a proporção de indivíduos resistentes e suscetíveis estava de acordo com a esperada. No caso de segregação de um alelo de resistência dominante e de retrocruzamento com o parental suscetível, esta seria de 1:1. A co-segregação entre gene e marcadores candidatos foi analisada admitindo-se segregação independente entre gene e cada fragmento polimórfico como hipótese nula, ou seja, ausência de ligação entre os mesmos. No caso de marcador presente no genitor resistente, por exemplo, a proporção entre indivíduos resistentes com presença do fragmento, resistentes sem presença do fragmento, suscetíveis com fragmento e suscetíveis sem fragmento seria de 1:1:1:1. No caso de o valor de $\chi^{2}$ ser significativo, admitiu-se a hipótese alternativa de ligação entre gene e fragmento. A distância entre gene e marcador foi então calculada com base na porcentagem de indivíduos recombinantes. Por exemplo, havendo $1 \%$ de indivíduos recombinantes, assume-se como distância aproximada entre gene e marcador 1cM. Assim, quanto menor a porcentagem de recombinantes, mais proximamente ligados estão gene e marcador. Para porcentagens de recombinantes maiores do que 1\%, este conceito não deve ser utilizado indiscriminadamente pois, devido à possibilidade de ocorrência de mais de um crossing-over entre marcador e gene, o número de recombinantes e, por 
conseguinte o cálculo da distância, costumam ser subestimados. Uma das maneiras de corrigir estes dados é através do emprego da fórmula de Kosambi:

$$
-d=0,25 \ln [(1+2 \theta) /(1-2 \theta)]
$$

onde, d representa a distância entre gene e marcador em centiMorgans e $\theta$ é a fração de indivíduos recombinantes. Assim, neste trabalho foi empregada esta fórmula, para porcentagens de recombinantes maiores que $1 \%$. 


\section{Resultados e Discussão}

\subsection{Avaliação da resistência de plantas da população RC1F1 a PRSV-W}

Foi possível distinguir com facilidade indivíduos suscetíveis de indivíduos resistentes, uma vez que os primeiros apresentaram sintomas inequívocos de mosaico enquanto os resistentes apresentaram sintomas intensos de hipersensibilidade (Figura 1). Convém ressaltar que os sintomas de hipersensibilidade iguais aos representados na referida figura resultam da inoculação mecânica com grande quantidade de inóculo. Em condições naturais, estes sintomas não ocorrem pois a infecção se dá através da picada de prova de afídeos, quando é inserida pequena quantidade de partículas virais em um ou poucos pontos.

Os sintomas de suscetibilidade e resistência observados no ensaio foram semelhantes aos descritos por Pitrat \& Lecoq (1984), citados por Pitrat (1991). Segundo estes autores, o vírus causa mosaico e deformações foliares em plantas suscetíveis e lesões necróticas em plantas resistentes inoculadas sem a presença de sintomas sistêmicos. Durante a fenotipagem, ainda foi possível observar clara distinção nas reações das linhagens parentais, tendo sido observado mosaico apenas na linhagem suscetível AF426 (Figura 2).

A proporção entre o número de plantas resistentes e suscetíveis (113:84) não diferiu estatisticamente daquela esperada no caso de segregação de um gene dominante de resistência $(98,5: 98,5)$ segundo o teste $\chi^{2}$ com $\alpha=$ 1\% (Tabela 2). Estes resultados eram esperados, uma vez que a resistência ao vírus PRSV-W é do tipo monogênica dominante (Pitrat, 2002; Pitrat, 1998; Pitrat \& Lecoq, 1983; Webb, 1979). 


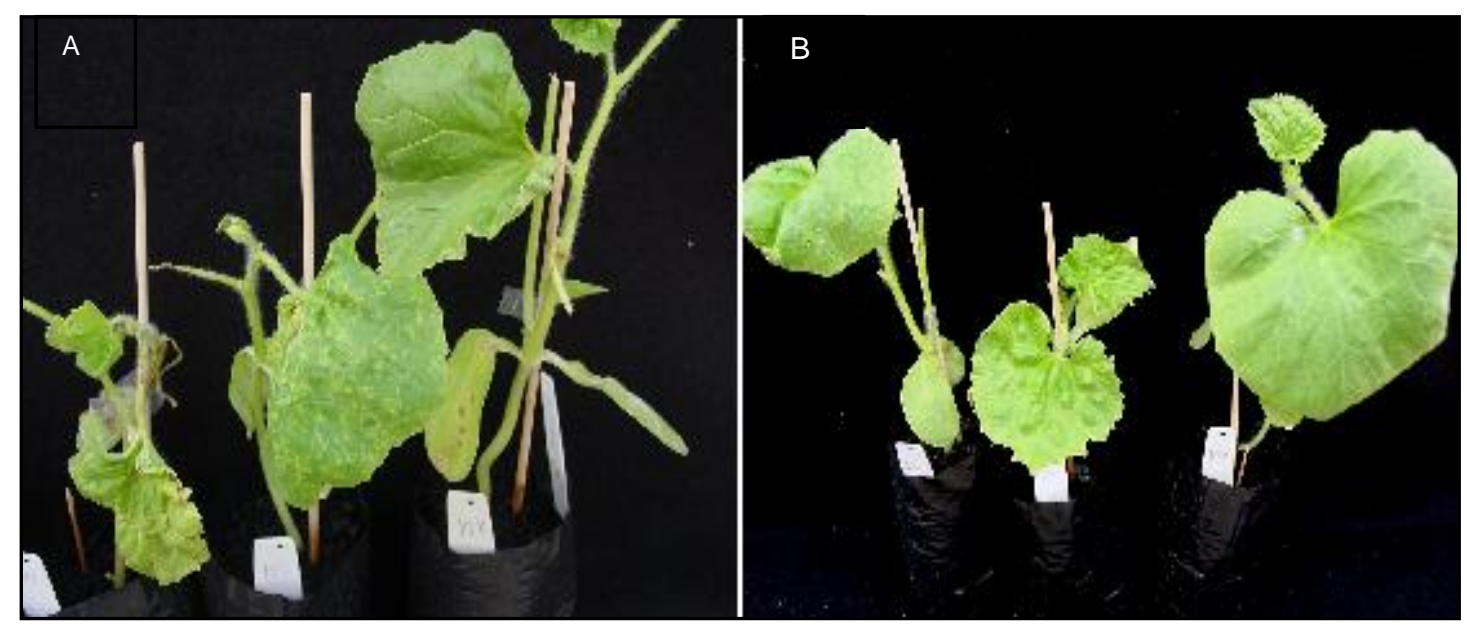

Figura 1 - A - Plantas resistentes da população de retrocruzamento (P2XP1)XP1 com fortes sintomas de hipersensibilidade; B - Plantas suscetíveis da mesma população com sintomas de mosaico causados pelo vírus PRSV-W

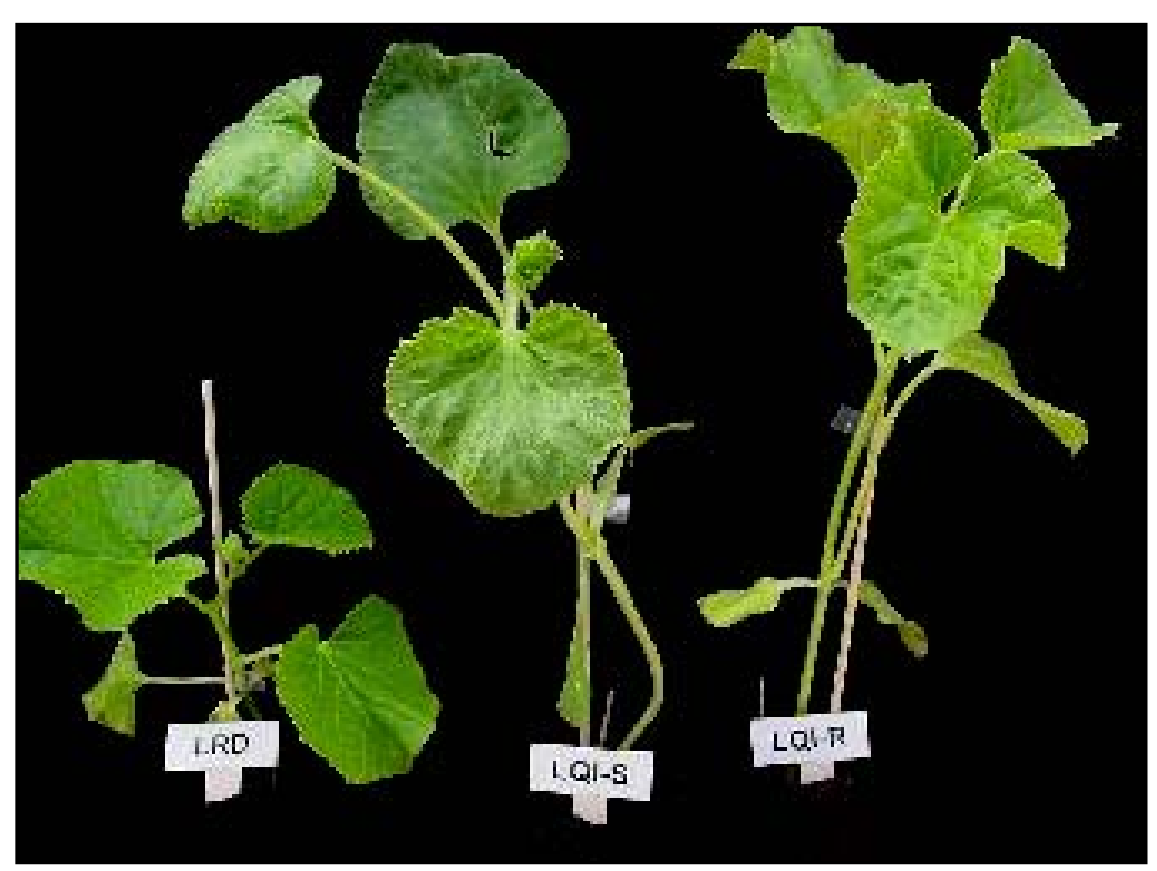

Figura 2 - Reações das linhagens parentais ao PRSV-W. Da esquerda para a direita vêem-se a linhagem P3 doadora do gene (LRD), a linhagem (P1) quase isogênica suscetível (LQI-S) e a linhagem (P2) quase isogênica resistente (LQI-R) 
Tabela 2. Resultados da avaliação da população RC1F1 à inoculação com PRSV-W e resultado do teste de $\chi^{2}$

\begin{tabular}{lccc}
\hline & Indivíduos resistentes & Indivíduos suscetíveis & $\chi^{2}(\alpha=1 \%)$ \\
\hline Valores observados & 113 & 84 & $4,27^{\mathrm{ns}}$ \\
Valores esperados & 98,5 & 98,5 & \\
\hline
\end{tabular}

\subsection{Genotipagem das linhagens e população RC1F1 por meio de AFLP}

Ao todo foram testadas 474 combinações diferentes de iniciadores, sendo $30 \mathrm{com}$ iniciadores do tipo Pst I+NNN em conjunto com Mse I+NNN. Os trabalhos realizados com estas não foram levados adiante, uma vez que foram observados fragmentos na linhagem quase isogênica resistente (LQI-R) que não foram observados nem na linhagem doadora (LDR) nem na linhagem quase isogênica suscetível (LQI-S). A LQI-R é oriunda de cruzamento realizado entre as outras duas linhagens e, portanto, não é possível que ela contenha fragmentos (ou alelos marcadores) não observados na LQI-S nem na LRD, salvo um raro caso de mutação. Estes fragmentos podem resultar de irregularidades na digestão enzimática. Entre os fenômenos que podem levar à digestão parcial estão o não reconhecimento de alguns sítios de restrição pela enzima Pst I devido à metilação de bases ou a ocorrência de atividade estrela por parte da enzima (http://arbl.cvmbs.colostate.edu/hbooks/genetics/biotech/ enzymes/cuteffects.html).

A metilação, ou adição de um grupo metil a uma citosina, pode alterar o reconhecimento de alguns sítios de restrição e está associada a diversos processos biológicos, incluindo regulação transcricional e silenciamento gênico (Cervera et al., 2002). Mudanças no padrão de metilação podem ocorrer devido a metilação "de novo" ou por demetilação passiva devido a falhas na manutenção da metilação durante a replicação do DNA (Matsuo et al., 1998; 
Hsieh, 1999, citados por Cervera et al., 2002). Algumas enzimas, dentre elas Pstl, são sensíveis à metilação, o que pode explicar o aparecimento dos fragmentos inespecíficos em questão (Vuylsteke et al., 2000; Barret \& Kidwell, 1998). Por outro lado, atividade estrela, que se refere à clivagem do DNA em sítios não convencionais, pode ocorrer devido a alterações nas condições da reação de digestão. São exemplos destas alterações pequenas variações de

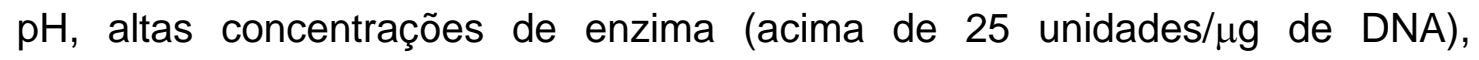
concentração iônica e tipos de íons presentes, cofatores outros que não $\mathrm{Mg}^{2+}$, como, por exemplo, $\mathrm{Mn}^{2+}$, e a presença de glicerol ou etilenoglicol (http://www.promega.com/guides/re_guide/chapone/ 1_4.htm).

$\mathrm{Na}$ tentativa de otimizar a digestão e obter DNA digerido de maneira homogênea, as condições de digestão com estas enzimas foram alteradas, incluindo aumento do tempo de digestão e utilização de concentrações diferentes de enzima Pstl. No entanto, todas as tentativas foram frustradas.

Das 444 combinações de iniciadores restantes, 100 foram do tipo EcoRI+ANN / Msel+CNN, 8 ECoRI+CA / Msel+CNN, 11 EcoRI+TA / Msel+CNN, 11 de EcoRI+AT / Msel+CNN, 10 EcoRI+CA / Msel+GNN, 14 EcoRI+TA / Msel+GNN, 16 EcoRI+AT / Msel+GNN, 181 EcoRI+TNN / Msel+GNN, 10 HindIII+ANN / Msel+ANN, 9 HindIII+CNN / Msel+ANN, 37 HindIII+ANN / Msel+GNN, 12 HindIII+CNN / Msel+GNN, 19 HindIII+ANN / Msel+CNN e 6 HindIII+CNN / Msel+CNN.

As amplificações realizadas com ambos primers contendo 3 nucleotídeos seletivos apresentaram perfis eletroforéticos com 58 fragmentos em média, enquanto as combinações realizadas com um primer com 2 nucleotídeos seletivos e um primer com 3 apresentaram, em média, 110 fragmentos. Ao todo, foram analisados aproximadamente 28.700 fragmentos. Destes, cerca de 8,6\% (2462 fragmentos) foram polimórficos entre a linhagem doadora e as quase isogênicas e, destes, apenas 5 foram polimórficos entre as linhagens quase isogênicas, todos obtidos com a combinação enzimática HindIII/Msel. 
Apesar da grande diversidade fenotípica observada entre as linhagens quase-isogênicas e a doadora, o pequeno número de fragmentos polimórficos (8,6\%) está de acordo com a literatura, que relata baixa ou nenhuma variabilidade intraespecífica para Cucumis melo (Dane, 1983; PerlTreves et al., 1986; Neuhausen, 1992; Shattuck-Eidens et al., 1990). Silberstein et al. (1999), por exemplo, utilizando a técnica RFLP, constataram 24\% de variabilidade entre a variedade mormodica e cultivares européias da variedade cantalupensis, enquanto que as variedades cantalupensis e inodorus apresentaram pequena variabilidade genética. Estes autores concluíram que as variedades cantalupensis e inodorus devem ter evoluído de ancestrais comuns em programas de melhoramento, sendo atualmente observada maior variabilidade apenas entre variedades selvagens e cultivadas.

Quando analisados apenas os perfis eletroforéticos obtidos com a utilização das enzimas EcoRI e Msel, não foi verificado nenhum polimorfismo entre as LQIs. A ausência de polimorfismos entre estas linhagens, mesmo após a utilização de 351 combinações diferentes de iniciadores é devida, provavelmente, ao fato de haver maior concentração de sítios de restrição da enzima EcoRI na região centromérica em diversas espécies vegetais. Esta falta de aleatoriedade na distribuição de sítios de restrição de EcoR I foi mencionada por Castiglioli et al. (1999), que constataram haver alto grau de agrupamento destas seqüências na região centromérica e no cromossomo 1 de milho, enquanto genes parecem estar concentrados em regiões não centroméricas (Carels et al., 1995). Outros trabalhos citados por Castiglioli et al. (1999) citam a ocorrência de agrupamentos de sítios de restrição da enzima EcoR I para as seguintes culturas: cevada (Castiglioli et al., 1998), trigo (Hart, 1994), arroz (Nandi et al., 1997) e batata (VanEck et al., 1995).

Dos cinco fragmentos polimórficos entre as LQIs, apenas três foram reproduzidos em amplificações independentes, apresentando-se também polimórficos nos indivíduos fenotipados da população segregante. Estes fragmentos polimórficos foram denominados de EA270, HF155 e EK190 
(Figuras 3, 4 e 5), amplificados com os primers Msel+GTG / HindIII+ATG, Msel+GTA / HindIII+ACA e Msel+GTG / HindIII+CGA, respectivamente.

Segundo Fehr (1997), a proporção média esperada do genoma do parental recorrente LQI-S recuperada no genoma da linhagem convertida LQI-R, pode ser estimada mediante a seguinte fórmula, elaborada por Allard (1960):

$$
P_{\text {LQI-S }}=1-(1 / 2)^{\mathrm{n}+1}
$$

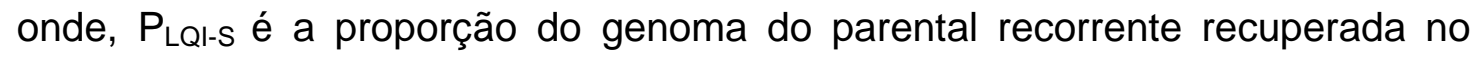
genoma da LQI-R e n é o número de retrocruzamentos para o parental recorrente

Logo, como neste caso foram realizados cinco retrocruzamentos, a porcentagem esperada do genoma da LQI-S no genoma da LQI-R é de aproximadamente $98,44 \%$. Dos 2.462 polimorfismos observados entre as linhagens, apenas 3 ocorreram entre as LQIs, o que resulta em uma porcentagem $0,12 \%$ de polimorfismos entre as mesmas, ou a uma recuperação do genoma do parental recorrente de 99,98\%, valor este próximo ao esperado pela fórmula dada.

\subsection{Análise de ligação entre marcadores ligados a gene de resistência a PRSV-W em pepino e gene de resistência a PRSV de melão}

Os marcadores ligados ao gene de resistência a PRSV-W em pepino descritos por Park et al. (2000) não foram amplificados nas linhagens de melão e tampouco foram observados outros polimorfismos entre as linhagens resistentes e a suscetível. De fato, Park et al. (2000), afirmam que os genes de resistência a PRSV-W e ZYMV em pepino estão ligados proximamente (2,2 cM) situando-se os marcadores no próprio gene de resistência a ZYMV e a 5,2 cM deste ponto. Já Pitrat (1991) relatou a construção de oito grupos de ligação para Cucumis melo que incluíam os genes de resistência a PRSV-W e ZYMV, mas estes mesmos genes mostravam-se em grupos diferentes. De posse destas 
informações foi possível concluir que não foram observados polimorfismos entre as LQIs devido à independência entre os dois genes de resistência ou ainda pela provável ocorrência de genes de resistência a PRSV-W distintos entre as duas espécies.

\subsection{Análise de ligação entre marcadores candidatos e gene de resistência a PRSV-W}

A proporção entre o número de indivíduos com presença e ausência do fragmento EA270 (106:79) não diferiu estatisticamente daquela esperada no caso de uma população RC1F1 $(92,5: 92,5)$, segundo teste $\chi^{2}$ com $\alpha=1 \%$ (Tabela 3; $\chi^{2}=4,88$ ), indicando não haver distorção de segregação do alelo marcador (Figura 3). A análise de ligação entre este marcador e o gene de resistência revelou que a proporção de indivíduos resistentes com e sem fragmento e suscetíveis com e sem amplificação do fragmento (75:32:31:47) diferiu estatisticamente daquela esperada pela hipótese de segregação independente entre gene e marcador $(46,25: 46,25: 46,25: 46,25)$ segundo teste $\chi^{2}$, com $\alpha=1 \%$ (Tabela $3 ; \chi^{2}=27,3$ ). Desta forma, infere-se a existência de ligação entre o loco marcador EA270 e o gene Prv' ${ }^{1}$. O número total de indivíduos recombinantes foi de 33,7\% entre os 185 indivíduos da população que foram genotipados (Tabela 4; Anexo).

A análise da segregação do loco marcador HF155 indicou forte ligação ao loco EA270, não sendo encontrados indivíduos recombinantes, ou seja, com a presença de um dos fragmentos e ausência do outro. Logo, concluise que HF155 também está ligado ao gene $\operatorname{PrV}^{1}$ (Tabela 5; Anexo). 
Tabela 3. Número de plantas resistentes e suscetíveis com presença ou ausência dos fragmentos EA270 e HF155 na população RC1F1 avaliada quanto à resistência a PRSV-W. Números entre parênteses indicam os valores esperados no caso de segregação independente entre gene e marcador

\begin{tabular}{cccc}
\hline & Indivíduos resistentes & Indivíduos suscetíveis & Total \\
\hline Presença de fragmento & $75(46,25)$ & $31(46,25)$ & $106(92,5)$ \\
Ausência de fragmento & $32(46,25)$ & $47(46,25)$ & $79(92,5)$ \\
\hline Total & $107(92,5)$ & $78(92,5)$ & 185 \\
\hline
\end{tabular}

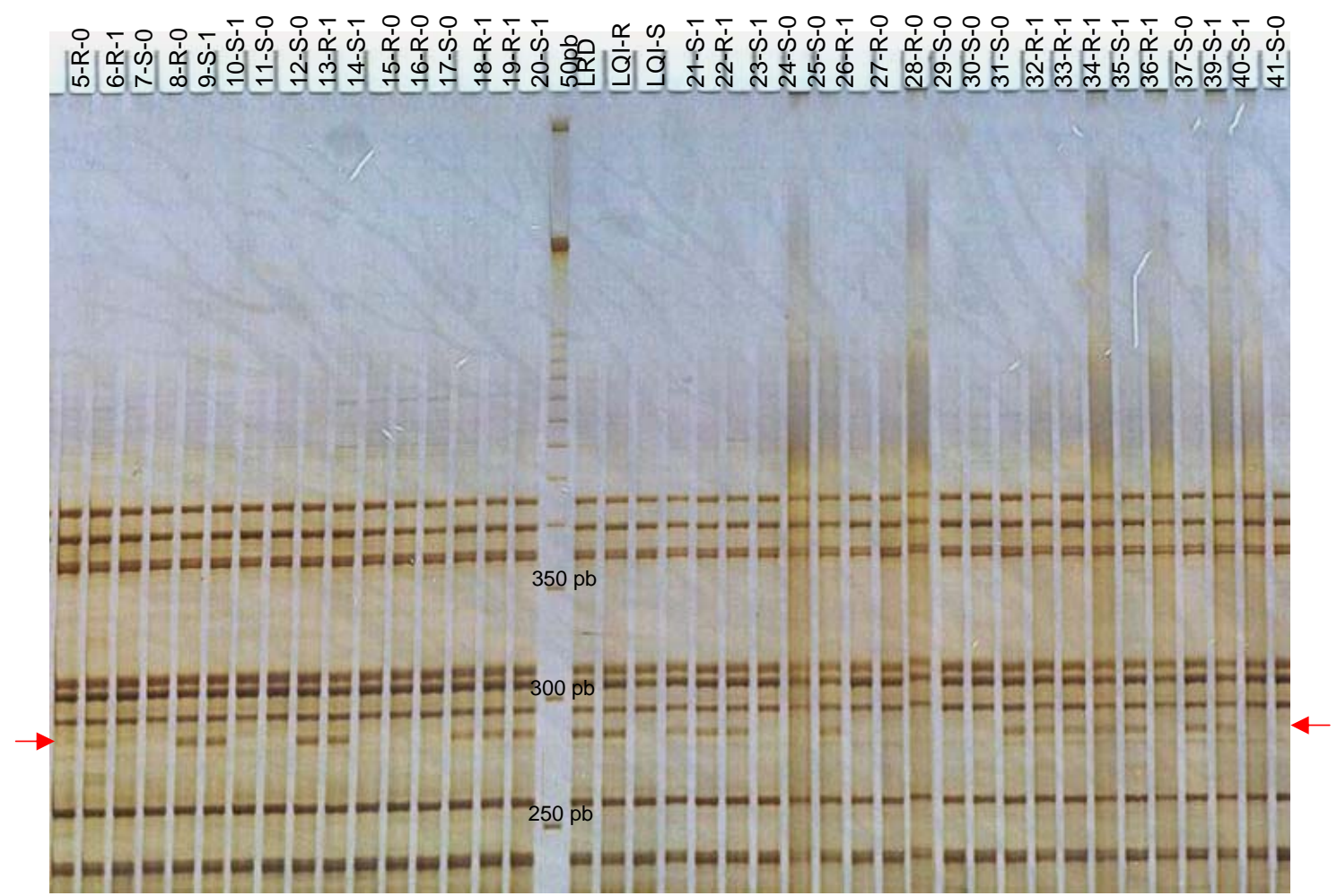

Figura 3 - Gel de acrilamida onde aparece o polimorfismo EA270 indicado pelas setas. LRD = linhagem doadora do gene; LQI-R = linhagem quase isogênica resistente; LQI-S = linhagem quase isogênica suscetível; 5 42 = população segregante RC1F1 $(\mathrm{R}$ = resistente; $\mathrm{S}=$ suscetível; 0 = ausência do fragmento; 1 = presença do fragmento) 
Para cálculo da distância entre gene e estes marcadores foi utilizada a fórmula de Kosambi, obtendo-se valor provável de 40,9 cM, valor este que impossibilita a utilização destes marcadores para seleção assistida (SAM), devido à elevada freqüência esperada de recombinação entre locos marcadores e gene ao longo dos ciclos de seleção.

A proporção entre o número de indivíduos com presença e com ausência do fragmento EK190 (111:77) não diferiu estatisticamente daquela esperada no caso de segregação mendeliana do mesmo (94:94) segundo teste $\chi^{2}$, com $\alpha=1 \%$ (Tabela 6; $\left.\chi^{2}=6,15\right)$. Assumindo-se a hipótese de segregação independente entre gene e marcador, a proporção de indivíduos resistentes com e sem presença do fragmento e suscetíveis com sem amplificação do fragmento (110:0:1:77) diferiu estatisticamente daquela esperada (47:47:47:47) segundo teste $\chi^{2}$, com $\alpha=1 \%$ (Tabela 6). Este fragmento encontra-se proximamente ligado ao gene de resistência em estudo, havendo sido observada apenas a presença de um único indivíduo recombinante entre os 188 indivíduos analisados (Tabela 7; Anexo). Como em toda a população estudada apenas $0,526 \%$ dos indivíduos foram recombinantes, pode-se inferir que a distância entre gene e marcador é de aproximadamente 0,526 cM.

Este é o primeiro relato de um marcador molecular proximamente ligado ao gene $P r v^{1}$ em melão. Marcadores moleculares deste tipo podem ser utilizados no desenvolvimento de marcadores SCAR (Sequence Characterized Amplified Regions) que possuem a vantagem de permitir determinação de genótipos através de processos mais rápidos que AFLP, já que só exigem $\mathrm{PCR}$ e eletroforese em agarose. Isto permitiria sua fácil utilização em programas com seleção assistida por marcadores.

Tabela 6. Número de plantas resistentes e suscetíveis com presença ou ausência do fragmento EK190 na população RC1F1 avaliada quanto à resistência a PRSV-W. Números entre parênteses indicam os valores esperados no caso de segregação independente entre gene e marcador

\begin{tabular}{cccc}
\hline & Indivíduos resistentes & Indivíduos suscetíveis & Total \\
\hline Presença de fragmento & $110(47)$ & $1(47)$ & $111(94)$ \\
Ausência de fragmento & $0(47)$ & $77(47)$ & $77(94)$ \\
\hline Total & $110(94)$ & $78(94)$ & 188 \\
\hline
\end{tabular}




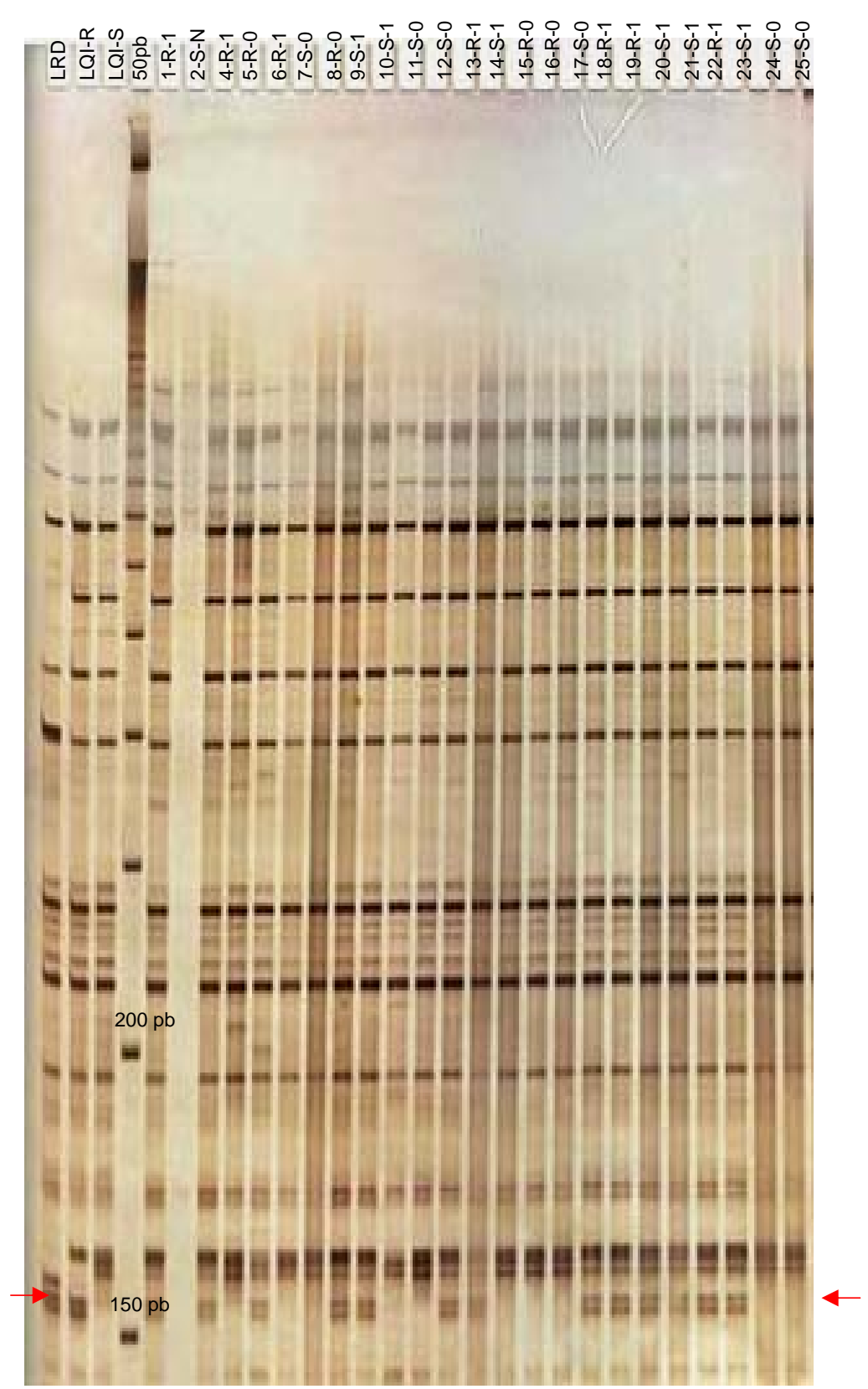

Figura 4 - Gel de acrilamida onde aparece o polimorfismo HF155 indicado pelas setas. LRD = linhagem doadora do gene; LQI-R = linhagem quase isogênica resistente; LQI-S = linhagem quase isogênica suscetível; 125 = população segregante RC1F1 $(\mathrm{R}=$ resistente; $\mathrm{S}=$ suscetível; 0 = ausência do fragmento; 1 = presença do fragmento; $N=$ falha de amplificação) 


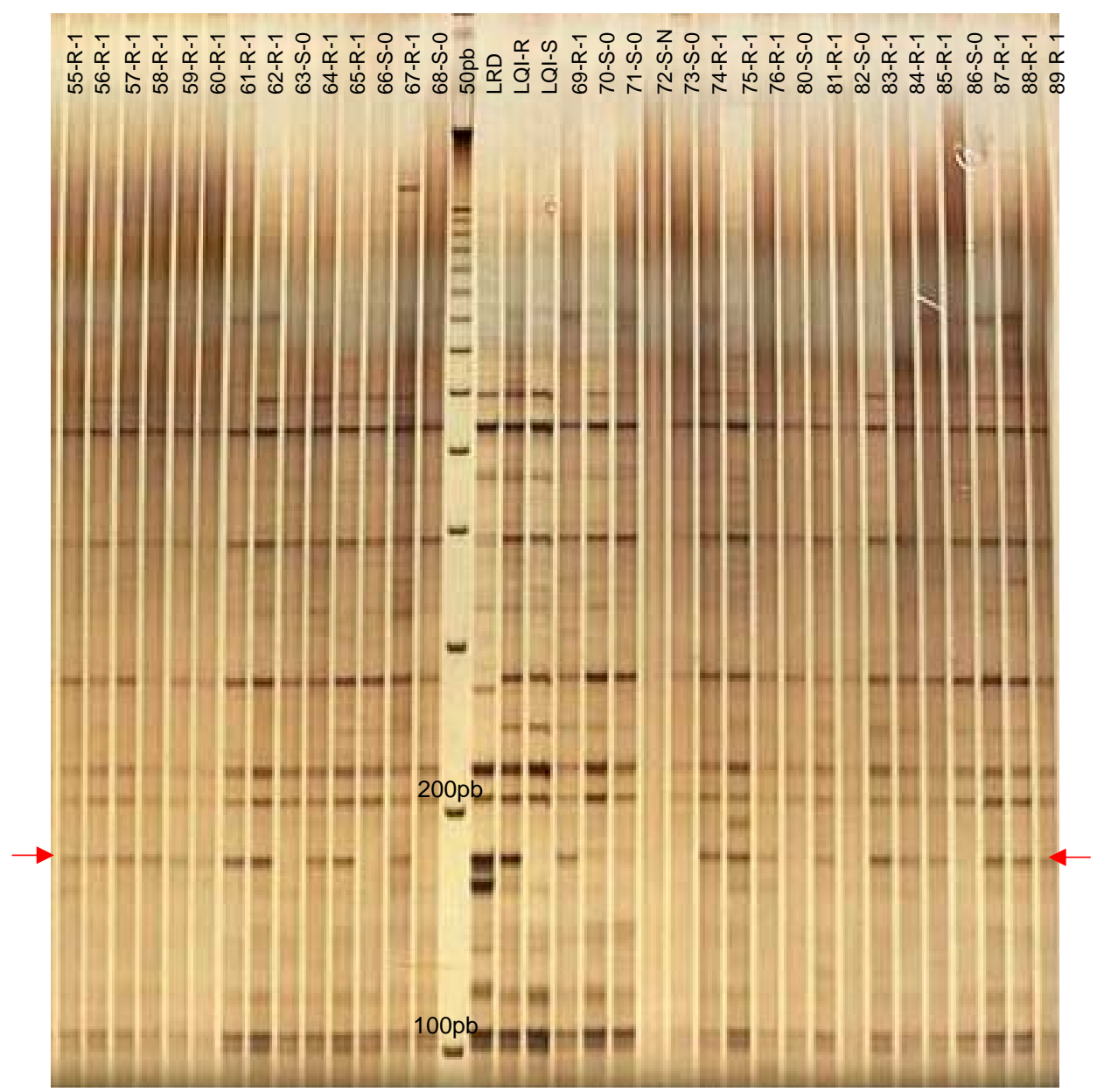

Figura 5 - Gel de acrilamida onde aparece o polimorfismo EK190 indicado pelas setas. $\mathrm{LRD}=$ linhagem doadora do gene; LQI-R = linhagem quase isogênica resistente; LQI-S = linhagem quase isogênica suscetível; 55-89 = população segregante RC1F1 (R = resistente; $\mathrm{S}$ = suscetível; 0 = ausência do fragmento; 1 = presença do fragmento; $N=$ falha de amplificação) 


\section{CONCLUSÕES}

1 - A diversidade genética existente entre as linhagens de melão amarelo testadas e a linhagem do tipo charentais foi de $8,6 \%$.

2- A técnica AFLP foi eficiente na detecção de marcadores moleculares ligados a gene de resistência em melão.

3- A estimativa de recuperação do genoma do parental recorrente na LQI-R foi de aproximadamente $99,98 \%$.

4- Os fragmentos EA270, HF155 e EK190 encontram-se ligados ao gene de resistência a PRSV-W, sendo a distância entre os mesmos de 40,9 cM, 40,9 $\mathrm{cM}$ e $0,0526 \mathrm{cM}$, respectivamente. Estes fragmentos foram considerados marcadores do gene Prv'.

5- Os marcadores EA270 e HF155 estão proximamente ligados.

6- O marcador EK190 pode ser utilizado em programas de melhoramento com seleção assistida por marcadores devido à sua grande proximidade do gene $P r v^{1}$, o que permitiria grande precisão durante o processo. 
ANEXOS 
Tabela 4. Resultados da fenotipagem (Fen) e da genotipagem (Gen) da população segregante RC1F1 para o fragmento EA270. R=resistente, $S=$ suscetível, $1=$ presença do fragmento e $0=$ ausência do fragmento

\begin{tabular}{|c|c|c|c|c|c|c|c|c|c|c|c|}
\hline Indiv. & Fen. & Gen. & Indiv. & Fen. & Gen. & Indiv. & Fen. & Gen. & Indiv. & Fen. & Gen. \\
\hline LRD & $\mathrm{R}$ & 1 & 49 & $\mathrm{~S}$ & 0 & 99 & S & 0 & 149 & $\mathrm{R}$ & 1 \\
\hline LQI-R & $\mathrm{R}$ & 1 & 50 & S & 1 & 100 & S & 0 & 150 & $\mathrm{R}$ & 0 \\
\hline LQI-S & $S$ & 0 & 51 & $S$ & 1 & 101 & $S$ & 0 & 151 & $S$ & 1 \\
\hline 1 & $\mathrm{R}$ & 1 & 52 & $\mathrm{R}$ & 1 & 102 & $\mathrm{R}$ & 1 & 152 & $\mathrm{R}$ & 1 \\
\hline 2 & S & 0 & 53 & $\mathrm{R}$ & 1 & 103 & $\mathrm{R}$ & 0 & 153 & $\mathrm{R}$ & 1 \\
\hline 3 & $\mathrm{R}$ & - & 54 & $\mathrm{R}$ & 0 & 104 & $\mathrm{R}$ & 1 & 154 & $\mathrm{R}$ & 0 \\
\hline 4 & $\mathrm{R}$ & 1 & 55 & $\mathrm{R}$ & 1 & 105 & S & 0 & 155 & S & 0 \\
\hline 5 & $\mathrm{R}$ & 0 & 56 & $\mathrm{R}$ & 1 & 106 & $\mathrm{R}$ & 1 & 156 & $\mathrm{R}$ & 1 \\
\hline 6 & $\mathrm{R}$ & 1 & 57 & $\mathrm{R}$ & 1 & 107 & $S$ & 0 & 157 & $\mathrm{R}$ & 0 \\
\hline 7 & $\mathrm{~S}$ & 0 & 58 & $\mathrm{R}$ & 1 & 108 & $\mathrm{R}$ & 1 & 158 & $\mathrm{R}$ & 1 \\
\hline 8 & $\mathrm{R}$ & 0 & 59 & $\mathrm{R}$ & 1 & 109 & $\mathrm{R}$ & 0 & 159 & $\mathrm{R}$ & 1 \\
\hline 9 & $\mathrm{~S}$ & 1 & 60 & $\mathrm{R}$ & 0 & 110 & $\mathrm{R}$ & 1 & 160 & $\mathrm{~S}$ & 0 \\
\hline 10 & S & 1 & 61 & $\mathrm{R}$ & 0 & 111 & $\mathrm{R}$ & 1 & 161 & $\mathrm{R}$ & 1 \\
\hline 11 & S & 0 & 62 & $\mathrm{R}$ & 1 & 112 & S & 0 & 162 & $\mathrm{R}$ & 1 \\
\hline 12 & S & 0 & 63 & S & 1 & 113 & $\mathrm{R}$ & 1 & 163 & $\mathrm{R}$ & 1 \\
\hline 13 & $\mathrm{R}$ & 1 & 64 & $\mathrm{R}$ & 0 & 114 & $\mathrm{R}$ & - & 164 & $\mathrm{R}$ & 1 \\
\hline 14 & S & 1 & 65 & $\mathrm{R}$ & 1 & 115 & S & 0 & 165 & $\mathrm{R}$ & 1 \\
\hline 15 & $\mathrm{R}$ & 0 & 66 & S & 0 & 116 & $\mathrm{R}$ & 1 & 166 & S & 0 \\
\hline 16 & $\mathrm{R}$ & 0 & 67 & $\mathrm{R}$ & 1 & 117 & $\mathrm{R}$ & - & 167 & $\mathrm{R}$ & 1 \\
\hline 17 & $\mathrm{~S}$ & 0 & 68 & $\mathrm{~S}$ & 1 & 118 & $\mathrm{~S}$ & 1 & 168 & $\mathrm{~S}$ & 1 \\
\hline 18 & $\mathrm{R}$ & 1 & 69 & $\mathrm{R}$ & 0 & 119 & $\mathrm{R}$ & 1 & 169 & $\mathrm{~S}$ & 0 \\
\hline 19 & $\mathrm{R}$ & 1 & 70 & S & 0 & 120 & $\mathrm{R}$ & 0 & 170 & $\mathrm{R}$ & 1 \\
\hline 20 & S & 1 & 71 & S & 0 & 121 & S & 1 & 171 & S & 1 \\
\hline 21 & S & 1 & 72 & S & 0 & 122 & S & 0 & 172 & $\mathrm{R}$ & 0 \\
\hline 22 & $\mathrm{R}$ & 1 & 73 & $\mathrm{~S}$ & 1 & 123 & $\mathrm{~S}$ & 1 & 173 & S & 0 \\
\hline 23 & S & 1 & 74 & $\mathrm{R}$ & 1 & 124 & $\mathrm{~S}$ & 0 & 174 & $\mathrm{R}$ & 0 \\
\hline 24 & $\mathrm{~S}$ & 0 & 75 & $\mathrm{R}$ & 1 & 125 & $\mathrm{R}$ & 1 & 175 & $\mathrm{R}$ & 1 \\
\hline 25 & $\mathrm{~S}$ & 0 & 76 & $\mathrm{R}$ & 1 & 126 & $\mathrm{~S}$ & 0 & 176 & $\mathrm{~S}$ & 1 \\
\hline 26 & $\mathrm{R}$ & 1 & 77 & $\mathrm{R}$ & 1 & 127 & $\mathrm{~S}$ & 0 & 177 & $\mathrm{R}$ & 1 \\
\hline 27 & $\mathrm{R}$ & 0 & 78 & $\mathrm{R}$ & 0 & 128 & $\mathrm{~S}$ & - & 178 & $\mathrm{R}$ & 1 \\
\hline 28 & $\mathrm{R}$ & 0 & 79 & $\mathrm{R}$ & 1 & 129 & $\mathrm{~S}$ & 1 & 179 & $\mathrm{R}$ & 1 \\
\hline 29 & $\mathrm{~S}$ & 0 & 80 & $S$ & 1 & 130 & $\mathrm{~S}$ & 1 & 180 & $\mathrm{~S}$ & 0 \\
\hline 30 & $\mathrm{~S}$ & 0 & 81 & $\mathrm{R}$ & 1 & 131 & $\mathrm{R}$ & 1 & 181 & $\mathrm{~S}$ & 0 \\
\hline 31 & S & 0 & 82 & S & 1 & 132 & $\mathrm{R}$ & 1 & 182 & $\mathrm{R}$ & 1 \\
\hline 32 & $\mathrm{R}$ & 1 & 83 & $\mathrm{R}$ & 0 & 133 & $\mathrm{R}$ & 1 & 183 & $\mathrm{~S}$ & 0 \\
\hline 33 & $\mathrm{R}$ & 1 & 84 & $\mathrm{R}$ & 0 & 134 & $\mathrm{R}$ & 0 & 184 & $\mathrm{R}$ & 1 \\
\hline 34 & $\mathrm{R}$ & 1 & 85 & $\mathrm{R}$ & 1 & 135 & $\mathrm{R}$ & 1 & 185 & $\mathrm{R}$ & 0 \\
\hline 35 & S & 1 & 86 & $S$ & 0 & 136 & $\mathrm{R}$ & 1 & 186 & $\mathrm{R}$ & 0 \\
\hline
\end{tabular}


Tabela 4. Resultados da fenotipagem (Fen) e da genotipagem (Gen) da população segregante RC1F1 para o fragmento EA270. R=resistente, S=suscetível, $1=$ presença do fragmento e $0=$ ausência do fragmento

\begin{tabular}{ccc|ccc|ccc|ccc}
\hline Indiv. & Fen. & Gen. & Indiv. & Fen. & Gen. & Indiv. & Fen. & Gen. & Indiv. & Fen. & Gen. \\
\hline 36 & $\mathrm{R}$ & 1 & 87 & $\mathrm{R}$ & 0 & 137 & $\mathrm{~S}$ & 0 & 187 & $\mathrm{~S}$ & 0 \\
37 & $\mathrm{~S}$ & 0 & 88 & $\mathrm{R}$ & 1 & 138 & $\mathrm{~S}$ & 1 & 188 & $\mathrm{R}$ & - \\
39 & $\mathrm{~S}$ & 1 & 89 & $\mathrm{R}$ & 1 & 139 & $\mathrm{~S}$ & 1 & 189 & $\mathrm{~S}$ & - \\
40 & $\mathrm{~S}$ & 1 & 90 & $\mathrm{R}$ & 1 & 140 & $\mathrm{R}$ & 1 & 190 & $\mathrm{~S}$ & - \\
41 & $\mathrm{~S}$ & 0 & 91 & $\mathrm{~S}$ & 1 & 141 & $\mathrm{R}$ & - & 191 & $\mathrm{~S}$ & 0 \\
42 & $\mathrm{R}$ & 0 & 92 & $\mathrm{R}$ & 1 & 142 & $\mathrm{~S}$ & 0 & 192 & $\mathrm{R}$ & 1 \\
43 & $\mathrm{~S}$ & - & 93 & $\mathrm{R}$ & 0 & 143 & $\mathrm{R}$ & 1 & 193 & $\mathrm{~S}$ & - \\
44 & $\mathrm{R}$ & 1 & 94 & $\mathrm{R}$ & 1 & 144 & $\mathrm{R}$ & 0 & 194 & $\mathrm{~S}$ & 0 \\
45 & $\mathrm{~S}$ & 0 & 95 & $\mathrm{~S}$ & 1 & 145 & $\mathrm{R}$ & 1 & 195 & $\mathrm{~S}$ & 0 \\
46 & $\mathrm{R}$ & 0 & 96 & $\mathrm{~S}$ & 1 & 146 & $\mathrm{R}$ & 1 & 196 & $\mathrm{~S}$ & - \\
47 & $\mathrm{~S}$ & 0 & 97 & $\mathrm{~S}$ & 1 & 147 & $\mathrm{~S}$ & 0 & 197 & $\mathrm{R}$ & 0 \\
48 & $\mathrm{R}$ & 1 & 98 & $\mathrm{R}$ & - & 148 & $\mathrm{~S}$ & 0 & 198 & $\mathrm{R}$ & 0 \\
\hline
\end{tabular}


Tabela 5. Resultados da fenotipagem (Fen) e da genotipagem (Gen) da população segregante RC1F1 para o fragmento HF155. R=resistente, $S=$ suscetível, $1=$ presença do fragmento e $0=$ ausência do fragmento

\begin{tabular}{|c|c|c|c|c|c|c|c|c|c|c|c|}
\hline Indiv. & Fen. & Gen. & Indiv. & Fen. & Gen. & Indiv. & Fen. & Gen. & Indiv. & Fen. & Gen. \\
\hline LRD & $\mathrm{R}$ & 1 & 49 & $\mathrm{~S}$ & 0 & 99 & S & 0 & 149 & $\mathrm{R}$ & 1 \\
\hline LQI-R & $\mathrm{R}$ & 1 & 50 & S & 1 & 100 & S & 0 & 150 & $\mathrm{R}$ & 0 \\
\hline LQI-S & $S$ & 0 & 51 & $S$ & 1 & 101 & $S$ & 0 & 151 & $S$ & 1 \\
\hline 1 & $\mathrm{R}$ & 1 & 52 & $\mathrm{R}$ & 1 & 102 & $\mathrm{R}$ & 1 & 152 & $\mathrm{R}$ & 1 \\
\hline 2 & S & 0 & 53 & $\mathrm{R}$ & 1 & 103 & $\mathrm{R}$ & 0 & 153 & $\mathrm{R}$ & 1 \\
\hline 3 & $\mathrm{R}$ & - & 54 & $\mathrm{R}$ & 0 & 104 & $\mathrm{R}$ & 1 & 154 & $\mathrm{R}$ & 0 \\
\hline 4 & $\mathrm{R}$ & 1 & 55 & $\mathrm{R}$ & 1 & 105 & S & 0 & 155 & S & 0 \\
\hline 5 & $\mathrm{R}$ & 0 & 56 & $\mathrm{R}$ & 1 & 106 & $\mathrm{R}$ & 1 & 156 & $\mathrm{R}$ & 1 \\
\hline 6 & $\mathrm{R}$ & 1 & 57 & $\mathrm{R}$ & 1 & 107 & $S$ & 0 & 157 & $\mathrm{R}$ & 0 \\
\hline 7 & $\mathrm{~S}$ & 0 & 58 & $\mathrm{R}$ & 1 & 108 & $\mathrm{R}$ & 1 & 158 & $\mathrm{R}$ & 1 \\
\hline 8 & $\mathrm{R}$ & 0 & 59 & $\mathrm{R}$ & 1 & 109 & $\mathrm{R}$ & 0 & 159 & $\mathrm{R}$ & 1 \\
\hline 9 & $\mathrm{~S}$ & 1 & 60 & $\mathrm{R}$ & 0 & 110 & $\mathrm{R}$ & 1 & 160 & $\mathrm{~S}$ & 0 \\
\hline 10 & S & 1 & 61 & $\mathrm{R}$ & 0 & 111 & $\mathrm{R}$ & 1 & 161 & $\mathrm{R}$ & 1 \\
\hline 11 & S & 0 & 62 & $\mathrm{R}$ & 1 & 112 & S & 0 & 162 & $\mathrm{R}$ & 1 \\
\hline 12 & S & 0 & 63 & S & 1 & 113 & $\mathrm{R}$ & 1 & 163 & $\mathrm{R}$ & 1 \\
\hline 13 & $\mathrm{R}$ & 1 & 64 & $\mathrm{R}$ & 0 & 114 & $\mathrm{R}$ & - & 164 & $\mathrm{R}$ & 1 \\
\hline 14 & S & 1 & 65 & $\mathrm{R}$ & 1 & 115 & S & 0 & 165 & $\mathrm{R}$ & 1 \\
\hline 15 & $\mathrm{R}$ & 0 & 66 & S & 0 & 116 & $\mathrm{R}$ & 1 & 166 & S & 0 \\
\hline 16 & $\mathrm{R}$ & 0 & 67 & $\mathrm{R}$ & 1 & 117 & $\mathrm{R}$ & - & 167 & $\mathrm{R}$ & 1 \\
\hline 17 & $\mathrm{~S}$ & 0 & 68 & $\mathrm{~S}$ & 1 & 118 & $\mathrm{~S}$ & 1 & 168 & $\mathrm{~S}$ & 1 \\
\hline 18 & $\mathrm{R}$ & 1 & 69 & $\mathrm{R}$ & 0 & 119 & $\mathrm{R}$ & 1 & 169 & $\mathrm{~S}$ & 0 \\
\hline 19 & $\mathrm{R}$ & 1 & 70 & S & 0 & 120 & $\mathrm{R}$ & 0 & 170 & $\mathrm{R}$ & 1 \\
\hline 20 & S & 1 & 71 & S & 0 & 121 & S & 1 & 171 & S & 1 \\
\hline 21 & S & 1 & 72 & S & 0 & 122 & S & 0 & 172 & $\mathrm{R}$ & 0 \\
\hline 22 & $\mathrm{R}$ & 1 & 73 & $\mathrm{~S}$ & 1 & 123 & $\mathrm{~S}$ & 1 & 173 & S & 0 \\
\hline 23 & S & 1 & 74 & $\mathrm{R}$ & 1 & 124 & $\mathrm{~S}$ & 0 & 174 & $\mathrm{R}$ & 0 \\
\hline 24 & $\mathrm{~S}$ & 0 & 75 & $\mathrm{R}$ & 1 & 125 & $\mathrm{R}$ & 1 & 175 & $\mathrm{R}$ & 1 \\
\hline 25 & $\mathrm{~S}$ & 0 & 76 & $\mathrm{R}$ & 1 & 126 & $\mathrm{~S}$ & 0 & 176 & $\mathrm{~S}$ & 1 \\
\hline 26 & $\mathrm{R}$ & 1 & 77 & $\mathrm{R}$ & 1 & 127 & $\mathrm{~S}$ & 0 & 177 & $\mathrm{R}$ & 1 \\
\hline 27 & $\mathrm{R}$ & 0 & 78 & $\mathrm{R}$ & 0 & 128 & $\mathrm{~S}$ & - & 178 & $\mathrm{R}$ & 1 \\
\hline 28 & $\mathrm{R}$ & 0 & 79 & $\mathrm{R}$ & 1 & 129 & $\mathrm{~S}$ & 1 & 179 & $\mathrm{R}$ & 1 \\
\hline 29 & $\mathrm{~S}$ & 0 & 80 & $S$ & 1 & 130 & $\mathrm{~S}$ & 1 & 180 & $\mathrm{~S}$ & 0 \\
\hline 30 & $\mathrm{~S}$ & 0 & 81 & $\mathrm{R}$ & 1 & 131 & $\mathrm{R}$ & 1 & 181 & $\mathrm{~S}$ & 0 \\
\hline 31 & S & 0 & 82 & S & 1 & 132 & $\mathrm{R}$ & 1 & 182 & $\mathrm{R}$ & 1 \\
\hline 32 & $\mathrm{R}$ & 1 & 83 & $\mathrm{R}$ & 0 & 133 & $\mathrm{R}$ & 1 & 183 & $\mathrm{~S}$ & 0 \\
\hline 33 & $\mathrm{R}$ & 1 & 84 & $\mathrm{R}$ & 0 & 134 & $\mathrm{R}$ & 0 & 184 & $\mathrm{R}$ & 1 \\
\hline 34 & $\mathrm{R}$ & 1 & 85 & $\mathrm{R}$ & 1 & 135 & $\mathrm{R}$ & 1 & 185 & $\mathrm{R}$ & 0 \\
\hline 35 & S & 1 & 86 & $S$ & 0 & 136 & $\mathrm{R}$ & 1 & 186 & $\mathrm{R}$ & 0 \\
\hline
\end{tabular}


Tabela 5. Resultados da fenotipagem (Fen) e da genotipagem (Gen) da população segregante RC1F1 para o fragmento HF155. R=resistente, $S=$ suscetível, $1=$ presença do fragmento e $0=$ ausência do fragmento

\begin{tabular}{ccc|ccc|ccc|ccc}
\hline Indiv. & Fen. & Gen. & Indiv. & Fen. & Gen. & Indiv. & Fen. & Gen. & Indiv. & Fen. & Gen. \\
\hline 36 & $\mathrm{R}$ & 1 & 87 & $\mathrm{R}$ & 0 & 137 & $\mathrm{~S}$ & 0 & 187 & $\mathrm{~S}$ & 0 \\
37 & $\mathrm{~S}$ & 0 & 88 & $\mathrm{R}$ & 1 & 138 & $\mathrm{~S}$ & 1 & 188 & $\mathrm{R}$ & - \\
39 & $\mathrm{~S}$ & 1 & 89 & $\mathrm{R}$ & 1 & 139 & $\mathrm{~S}$ & 1 & 189 & $\mathrm{~S}$ & - \\
40 & $\mathrm{~S}$ & 1 & 90 & $\mathrm{R}$ & 1 & 140 & $\mathrm{R}$ & 1 & 190 & $\mathrm{~S}$ & - \\
41 & $\mathrm{~S}$ & 0 & 91 & $\mathrm{~S}$ & 1 & 141 & $\mathrm{R}$ & - & 191 & $\mathrm{~S}$ & 0 \\
42 & $\mathrm{R}$ & 0 & 92 & $\mathrm{R}$ & 1 & 142 & $\mathrm{~S}$ & 0 & 192 & $\mathrm{R}$ & 1 \\
43 & $\mathrm{~S}$ & - & 93 & $\mathrm{R}$ & 0 & 143 & $\mathrm{R}$ & 1 & 193 & $\mathrm{~S}$ & - \\
44 & $\mathrm{R}$ & 1 & 94 & $\mathrm{R}$ & 1 & 144 & $\mathrm{R}$ & 0 & 194 & $\mathrm{~S}$ & 0 \\
45 & $\mathrm{~S}$ & 0 & 95 & $\mathrm{~S}$ & 1 & 145 & $\mathrm{R}$ & 1 & 195 & $\mathrm{~S}$ & 0 \\
46 & $\mathrm{R}$ & 0 & 96 & $\mathrm{~S}$ & 1 & 146 & $\mathrm{R}$ & 1 & 196 & $\mathrm{~S}$ & - \\
47 & $\mathrm{~S}$ & 0 & 97 & $\mathrm{~S}$ & 1 & 147 & $\mathrm{~S}$ & 0 & 197 & $\mathrm{R}$ & 0 \\
48 & $\mathrm{R}$ & 1 & 98 & $\mathrm{R}$ & - & 148 & $\mathrm{~S}$ & 0 & 198 & $\mathrm{R}$ & 0 \\
\hline
\end{tabular}


Tabela 7. Resultados da fenotipagem (Fen) e da genotipagem (Gen) da população segregante RC1F1 para o fragmento EK190. R=resistente, $S=$ suscetível, $1=$ presença do fragmento e $0=$ ausência do fragmento

\begin{tabular}{|c|c|c|c|c|c|c|c|c|c|c|c|}
\hline Indiv. & Fen. & Gen. & Indiv. & Fen. & Gen. & Indiv. & Fen. & Gen. & Indiv. & Fen. & Gen. \\
\hline LRD & $\mathrm{R}$ & 1 & 49 & $\mathrm{~S}$ & 0 & 99 & $\mathrm{~S}$ & 0 & 149 & $\mathrm{R}$ & 1 \\
\hline LQI-R & $\mathrm{R}$ & 1 & 50 & S & 0 & 100 & $\mathrm{~S}$ & - & 150 & $\mathrm{R}$ & 1 \\
\hline LQI-S & $\mathrm{S}$ & 0 & 51 & $\mathrm{~S}$ & 0 & 101 & $\mathrm{~S}$ & 0 & 151 & $S$ & 0 \\
\hline 1 & $\mathrm{R}$ & 1 & 52 & $\mathrm{R}$ & 1 & 102 & $\mathrm{R}$ & 1 & 152 & $\mathrm{R}$ & 1 \\
\hline 2 & $\mathrm{~S}$ & 0 & 53 & $\mathrm{R}$ & 1 & 103 & $\mathrm{R}$ & 1 & 153 & $\mathrm{R}$ & 1 \\
\hline 3 & $\mathrm{R}$ & 1 & 54 & $\mathrm{R}$ & 1 & 104 & $\mathrm{R}$ & 1 & 154 & $\mathrm{R}$ & 1 \\
\hline 4 & $\mathrm{R}$ & 1 & 55 & $\mathrm{R}$ & 1 & 105 & S & 0 & 155 & $\mathrm{~S}$ & 0 \\
\hline 5 & $\mathrm{R}$ & 1 & 56 & $\mathrm{R}$ & 1 & 106 & $\mathrm{R}$ & 1 & 156 & $\mathrm{R}$ & 1 \\
\hline 6 & $\mathrm{R}$ & 1 & 57 & $\mathrm{R}$ & 1 & 107 & $\mathrm{~S}$ & 0 & 157 & $\mathrm{R}$ & 1 \\
\hline 7 & S & 0 & 58 & $\mathrm{R}$ & 1 & 108 & $\mathrm{R}$ & 1 & 158 & $\mathrm{R}$ & 1 \\
\hline 8 & $\mathrm{R}$ & 1 & 59 & $\mathrm{R}$ & 1 & 109 & $\mathrm{R}$ & 1 & 159 & $\mathrm{R}$ & 1 \\
\hline 9 & $\mathrm{~S}$ & 0 & 60 & $\mathrm{R}$ & 1 & 110 & $\mathrm{R}$ & 1 & 160 & S & 0 \\
\hline 10 & $\mathrm{~S}$ & 0 & 61 & $\mathrm{R}$ & 1 & 111 & $\mathrm{R}$ & - & 161 & $\mathrm{R}$ & 1 \\
\hline 11 & $\mathrm{~S}$ & 0 & 62 & $\mathrm{R}$ & 1 & 112 & $\mathrm{~S}$ & 0 & 162 & $\mathrm{R}$ & 1 \\
\hline 12 & S & 0 & 63 & S & 0 & 113 & $\mathrm{R}$ & 1 & 163 & $\mathrm{R}$ & 1 \\
\hline 13 & $\mathrm{R}$ & 1 & 64 & $\mathrm{R}$ & 1 & 114 & $\mathrm{R}$ & 1 & 164 & $\mathrm{R}$ & 1 \\
\hline 14 & S & 0 & 65 & $\mathrm{R}$ & 1 & 115 & $S$ & 0 & 165 & $\mathrm{R}$ & 1 \\
\hline 15 & $\mathrm{R}$ & 1 & 66 & $\mathrm{~S}$ & 0 & 116 & $\mathrm{R}$ & 1 & 166 & S & 0 \\
\hline 16 & $\mathrm{R}$ & 1 & 67 & $\mathrm{R}$ & 1 & 117 & $\mathrm{R}$ & 1 & 167 & $\mathrm{R}$ & 1 \\
\hline 17 & $\mathrm{~S}$ & 0 & 68 & S & 0 & 118 & $\mathrm{~S}$ & 0 & 168 & $\mathrm{~S}$ & 0 \\
\hline 18 & $\mathrm{R}$ & 1 & 69 & $\mathrm{R}$ & 1 & 119 & $\mathrm{R}$ & 1 & 169 & $\mathrm{~S}$ & 0 \\
\hline 19 & $\mathrm{R}$ & 1 & 70 & S & 0 & 120 & $\mathrm{R}$ & 1 & 170 & $\mathrm{R}$ & 1 \\
\hline 20 & $\mathrm{~S}$ & 1 & 71 & S & 0 & 121 & S & 0 & 171 & $\mathrm{~S}$ & 0 \\
\hline 21 & S & 0 & 72 & $\mathrm{~S}$ & - & 122 & S & 0 & 172 & $\mathrm{R}$ & 1 \\
\hline 22 & $\mathrm{R}$ & 1 & 73 & S & 0 & 123 & $\mathrm{~S}$ & 0 & 173 & $\mathrm{~S}$ & 0 \\
\hline 23 & $S$ & 0 & 74 & $\mathrm{R}$ & 1 & 124 & $\mathrm{~S}$ & 0 & 174 & $\mathrm{R}$ & 1 \\
\hline 24 & $\mathrm{~S}$ & 0 & 75 & $\mathrm{R}$ & 1 & 125 & $\mathrm{R}$ & 1 & 175 & $\mathrm{R}$ & 1 \\
\hline 25 & $\mathrm{~S}$ & 0 & 76 & $\mathrm{R}$ & 1 & 126 & $\mathrm{~S}$ & 0 & 176 & $\mathrm{~S}$ & 0 \\
\hline 26 & $\mathrm{R}$ & 1 & 77 & $\mathrm{R}$ & 1 & 127 & $\mathrm{~S}$ & 0 & 177 & $\mathrm{R}$ & 1 \\
\hline 27 & $\mathrm{R}$ & 1 & 78 & $\mathrm{R}$ & 1 & 128 & $\mathrm{~S}$ & - & 178 & $\mathrm{R}$ & 1 \\
\hline 28 & $\mathrm{R}$ & 1 & 79 & $\mathrm{R}$ & 1 & 129 & $S$ & - & 179 & $\mathrm{R}$ & 1 \\
\hline 29 & $\mathrm{~S}$ & 0 & 80 & $S$ & 0 & 130 & $\mathrm{~S}$ & 0 & 180 & $\mathrm{~S}$ & 0 \\
\hline 30 & $S$ & 0 & 81 & $\mathrm{R}$ & 1 & 131 & $\mathrm{R}$ & 1 & 181 & S & 0 \\
\hline 31 & $S$ & 0 & 82 & S & 0 & 132 & $\mathrm{R}$ & - & 182 & $\mathrm{R}$ & 1 \\
\hline 32 & $\mathrm{R}$ & 1 & 83 & $\mathrm{R}$ & 1 & 133 & $\mathrm{R}$ & 1 & 183 & $\mathrm{~S}$ & 0 \\
\hline 33 & $\mathrm{R}$ & 1 & 84 & $\mathrm{R}$ & 1 & 134 & $\mathrm{R}$ & 1 & 184 & $\mathrm{R}$ & 1 \\
\hline 34 & $\mathrm{R}$ & 1 & 85 & $\mathrm{R}$ & 1 & 135 & $\mathrm{R}$ & 1 & 185 & $\mathrm{R}$ & 1 \\
\hline 35 & $S$ & 0 & 86 & $\mathrm{~S}$ & 0 & 136 & $\mathrm{R}$ & 1 & 186 & $\mathrm{R}$ & 1 \\
\hline
\end{tabular}


Tabela 7. Resultados da fenotipagem (Fen) e da genotipagem (Gen) da população segregante RC1F1 para o fragmento EK190. R=resistente, $S=$ suscetível, $1=$ presença do fragmento e $0=$ ausência do fragmento

\begin{tabular}{ccc|ccc|ccc|ccc}
\hline Indiv. & Fen. & Gen. & Indiv. & Fen. & Gen. & Indiv. & Fen. & Gen. & Indiv. & Fen. & Gen. \\
\hline 36 & $\mathrm{R}$ & 1 & 87 & $\mathrm{R}$ & 1 & 137 & $\mathrm{~S}$ & 0 & 187 & $\mathrm{~S}$ & - \\
37 & $\mathrm{~S}$ & 0 & 88 & $\mathrm{R}$ & 1 & 138 & $\mathrm{~S}$ & 0 & 188 & $\mathrm{R}$ & 1 \\
39 & $\mathrm{~S}$ & 0 & 89 & $\mathrm{R}$ & 1 & 139 & $\mathrm{~S}$ & 0 & 189 & $\mathrm{~S}$ & 0 \\
40 & $\mathrm{~S}$ & 0 & 90 & $\mathrm{R}$ & 1 & 140 & $\mathrm{R}$ & 1 & 190 & $\mathrm{~S}$ & 0 \\
41 & $\mathrm{~S}$ & 0 & 91 & $\mathrm{~S}$ & - & 141 & $\mathrm{R}$ & - & 191 & $\mathrm{~S}$ & 0 \\
42 & $\mathrm{R}$ & 1 & 92 & $\mathrm{R}$ & 1 & 142 & $\mathrm{~S}$ & 0 & 192 & $\mathrm{R}$ & 1 \\
43 & $\mathrm{~S}$ & 0 & 93 & $\mathrm{R}$ & 1 & 143 & $\mathrm{R}$ & 1 & 193 & $\mathrm{~S}$ & 0 \\
44 & $\mathrm{R}$ & 1 & 94 & $\mathrm{R}$ & 1 & 144 & $\mathrm{R}$ & 1 & 194 & $\mathrm{~S}$ & 0 \\
45 & $\mathrm{~S}$ & 0 & 95 & $\mathrm{~S}$ & 0 & 145 & $\mathrm{R}$ & 1 & 195 & $\mathrm{~S}$ & 0 \\
46 & $\mathrm{R}$ & 1 & 96 & $\mathrm{~S}$ & 0 & 146 & $\mathrm{R}$ & 1 & 196 & $\mathrm{~S}$ & 0 \\
47 & $\mathrm{~S}$ & 0 & 97 & $\mathrm{~S}$ & 0 & 147 & $\mathrm{~S}$ & 0 & 197 & $\mathrm{R}$ & 1 \\
48 & $\mathrm{R}$ & 1 & 98 & $\mathrm{R}$ & 1 & 148 & $\mathrm{~S}$ & 0 & 198 & $\mathrm{R}$ & 1 \\
\hline
\end{tabular}




\section{REFERÊNCIAS BIBLIOGRÁFICAS}

ALLARD, R.W. Principles of plant breeding. New York: John Wiley \& Sons, Inc., 1960. 485p.

ARUMUGANATHAN, K.; EARLE, E.D. Nuclear DNA content of some important plant species. Plant Molecular Biology Reporter, v.9, p.211-215, 1991.

BARRET, B.A.; KIDWELL, K.K. AFLP-based genetic diversity assessment among wheat cultivars from the Pacific Northwest. Crop Sience, v.38, n.5, 1261-1271, 1998.

BATESON, M.F.; HENDERSON, J.; CHALEEPROM, W.; GIBBS, A.J.; DALE, J.L. Papaya ringspot potyvirus: isolate variability and the origin of PRSV type P in Australia, Journal of General Virology, v.75, p.3547-353, 1994.

BATESON, M.F.; LINES, R.E.; REVILL, P.; CHALEEPROM, W.; HA, C.V.; GIBBS, A.J.; DALE, J.L. On the evolution and molecular epidemiology of the potyvirus Papaya ringspot virus, Journal of General Virology, v.83, p.25752585, 2002.

BLANCARD, D.; LECOQ, H.; PITRAT, M. A colour atlas of cucurbit diseases observation, identification \& control. USA: New York: McGraw - Hill, Inc., 1994. 299p. 
CARELS, N.; BARAKAT, A.; BERNARDI, G. The gene distribution of de maize genome. Proceedings of theNational Academic of Science of the USA, v.92, p. 11057-11060, 1995.

CASTIGLIOLI, P.; AJMONE-MARSAN, P.; VAN WIJK, R.; MOTTO, M. AFLP markers in a molecular linkage map of maize: codominant scoring and linkage group distribution, Theoretical and Applied Genetics, v.99, p. 425431, 1999.

CASTIGLIOLI, P.; POZZI, C.; HEUN, M; TERZI, V.; MULLER, K.J.; ROHDE, W.; SALAMINI, F. An AFLP-based for the efficiente mapping of mutations and DNA probes in barley. Genetics, v. 149, p. 2039-2056, 1998.

CERVERA, M.T.; RUIZ-GARCIA, L.; MARTINEZ-ZAPATER, J.M. Analysis of DNA methylation in Arabidopsis thaliana based on methylation-sensitive AFLP markers. Molecular Genetics and Genomics, v.268, p.543-552, 2002.

CRESTE, S.; TULMANN NETO, A.; FIGUEIRA, A. Detection of single sequence repeat polymorfisms in denaturing polyacrylamide sequencing gels by silver staining. Plant Molecular Biology Reporter, v.19, p.299-306, 2001.

DANE, F. Cucurbits, In: TANKSLEY, S.D.; ORTON, T.J. (Ed.). Isozymes in plant genetics and breeding. Elsevier: Amsterdan, Netherlands, 1983. Part B. 178p.

DANIN-POLEG, Y.; TZURI, G.; REIS N. Search for molecular markers Associated with resistance to viruses in melon. In: Meeting on Cucurbit Genetic \& Breeding, 7, p.321, 2000, Ma'ale Ha Hamisha, Israel. ISHS (Acta Horticulturae 510), 2000. 
DARYONO, B.S.; NATSUAKI, K.T. Application of Random Amplified Polymorphic DNA markers for detection of resistant cultivars of melon (Cucumis melo) against cucurbitaceae viruses. In: Meeting on Cucurbit Genetic \& Breeding, 9, 2002, Ma'ale Ha Hamisha, Israel. Proceedings $2^{\text {nd }}$ International Symposium on Cucurbits. Israel: ISHS, Acta Horticulturae, v.588, p. 321-329, 2002.

DIAZ, J.A.; MALLOR, C.; SORIA, C.; CAMERO, R.; GARZO, E.; FERERES, A.; ALVAREZ, J.M.; GÓMEZ-GUILLAMÓN, L.; LUIS-ARTEAGA, M.; MORIONES, E. Potencial sources of resistance for melon to nonpersistently aphid-borne viruses. Plant Disease, v.87, n.8, p.960-964, 2003.

FEHR, W.R. Principles of cultivar development. New York: McGraw - Hill, Inc., 1987. v.1, 536p.

FERREIRA, M. E., GRATTAPAGLIA, D. Introdução ao uso de marcadores moleculares em análise genética. $3^{\mathrm{a}}$ ed. Brasília: EMBRAPACENARGEN,1998.

FNP Consultoria \& Comércio. AGRIANUAL 2004: anuário da agricultura brasileira. São Paulo, 2003, p.414-415.

GARCIA-MAS, J.; OLIVER, M.; GÓMEZ-PANIAGUA, H.; DE VICENTE, M.V.. Comparing AFLP, RAPD and RFLP markers for measuring genetic diversity in melon. Theoretical and Applied Genetics, v.101, p. 860-864. 2000.

GIAMPAN, J.S.; REZENDE, J.A.M. Transmissibilidade por afídeos e reação de diversas espécies vegetais às estirpes fracas premunizantes do PRSV-W. Summa Phytopathologica, v.27, n.3, p.279-283, 2001. 
GONSALVES, D. Control of Papaya ringspot virus in papaya: a case study. Annual Review of Phytopathology, v.36, p.415-437, 1998.

GRAFTON-CARDWELL, E.E.; PERRING, T.M.; SMITH, R.F.; VALENCIA, J.; FERRAR, C.A. Ocurrence of mosaic viruses in melons in the central valley of California. Plant Disease, v.80, n.10, p.1092-1097, 1996.

GUIS, M. Biochemical and molecular markers. Melon Biotechnology. p. 304311, 1998.

HART, G.E. RFLP maps of bread wheat. In: PHILLIPS, R.L.; VASIL, I.K. (Ed.) DNA-based markers in plants. Netherlands: Kluwer Academic, 1994. 425p.

HOISINGTON, D.; KHAIRALLAH, M.; GONZÁLEZ DE LEON, D. Laboratory protocols. México: CYMMIT, 1994. 51p.

HSIEH, C.L. In vivo activity of murine de novo methyltransferases Dnmt3a and Dnmt3b. Molecular and Cell Biology, v.19, p.8211-8218, 1999.

JIMÉNEZ-DIÁZ, F. Maleza hospedera de virus, fluctuación problacional de vectores y su relación con enfermedades virales del melón (Cucumis melo L.) en la Comarca Lagunera, México. Revista Mexicana de Fitopatologia, v.14, n.1, p. 31-37, 1996.

KARSIES, T., DEAN, R., THOMAS, C. Toward the development of molecular markers linked to race 2 Fusarium wilt resistance in melon (Cucumis melo L.) In: Meeting on Cucurbit Genetic \& Breeding, 7, p. 246, 2000, Ma'ale Ha Hamisha, Israel. ISHS Acta Horticulturae, v.510, 2000. 
KUROZAWA, C.; PAVAN, M.A. Doenças das cucurbitáceas. In: KIMATI, H.; AMORIM, L.; BERGAMIN FILHO, A.; CAMARGO, L.E.A.; REZENDE, J.A.M. (Eds). Manual de fitopatologia - doenças das grandes culturas. São Paulo: Editora Agronômica Ceres Ltda., 1997. v.2, 774p.

LECOQ, H.; LOT, H.; PITRAT, M. Mise en evidence du virus de la mosaique de la pasteque type 1 (WMV-1) dans le Sud Est de la France, Agromomie, v.2, p. 787, 1982.

LUIS-ARTEAGA, M., ALVAREZ, J.M., ALONSO-PRADOS, J.L., BERNAL, J.J., GARCíA-ARENAL, F., LAVIÑA, A., BATLlE, A., MORIONES, E. Ocurrence, distribution and relative incidence of mosaic viruses infecting field-grown melon in Spain. Plant Disease, v.82, n.9, p.979-982, 1998.

MATSUO, K.; SILKE, J.; GEORGIEV, O.; MARTI, P.; GIOVANNINI, N.; RUNGGER, D. An embryonic demethylation mechanism involving binding of transcription factors to replicating DNA, EMBO Journal, v.17, p.1446-1453, 1998.

MUEHLBAUER, G.L.; SPECHT, J.E.; THOMAS-COMPTON, M.A.; STASWICK, P.E.; BERNARD, R.L. Near-isogenic lines - a potential resource in the integration of conventional and molecular marker linkage maps. Crop Science, v. 28, p. 729-735, 1988.

NANDI, S. SUBUDHI, P.K.; SENADHIRA, D.; MANIGBAS, N.L.; SEM-MANDI, S.; HUANG, N. Mapping QTLs for submergence tolerance in rice by AFLP analysis and selective genotyping. Molecular Genetics and Genomics., v. 255, p. 1-8, 1997.

NEUHAUSEN, S.L. Evaluation of restriction fragment lenght polymorphism in Cucumis melo. Theoretical and Applied Genetics 83, pp. 379-384, 1992. 
OLIVER, M., GARCIA-MAS, J., MORALES, M.. The Spanish melon genome project: Construction of a saturated genetic map. In: MEETING ON CUCURBIT GENETIC \& BREEDING, 7, p.437, 2000, Ma'ale Ha Hamisha, Israel. ISHS (Acta Horticulturae 510), 2001.

PARK, Y.H.; SENSOY, S.; CRISPIN, W.; ANTONISE, R.; PELEMAN, J.; HAVEY, M.J. A genetic map of cucumber composed of RAPDs, RFLPs, AFLPs and loci conditioning resistance to papaya ringspot and zucchini mosaic viruses. Genome, v.43, p. 1003-1010. 2000.

PATERSON, A.H. Genome mapping in plants. New York: Academic Press, 1996. p.71-83

PERL-TREVES, ZAMIR, R.; NAVOT, D.; GALUN, N. Phylogeny of Cucumis based on isozyme variability and its comparison with plastome phylogeny. Theoretical and Applied Genetics, v. 71, p. 430-436, 1986.

PITRAT, M. Linkage groups in Cucumis melo L. Journal of Heredity, v.82, p.406-411,1991.

PITRAT, M. Gene list for Cucumis melo L. Cucurbit Genetics Cooperative Reporter, v.13, p.58-70, 1998.

PITRAT, M. 2002 Gene list for melon. www.umresearch.umd.edu/CGC/ genelist/melon.pdf (May $16^{\text {th }}$ 2004).

PITRAT, M.; LECOQ, H. Two allele of Watermelon Mosaic Virus 1 resistance in melon. Cucurbit Genetics Cooperative Reporter, v.6, p.52-53, 1983.

PITRAT, M.; LECOQ, H. Inheritance of zuccini yellow mosaic virus resistance in Cucumis melo L. Euphytica, v.33, p.57-61, 1984. 
QUIOT-DOUINE, L.; LECOQ, H.; QUIOT, J.B.; PITRAT, M.; LABONNE, G. Serological and biological variability of virus isolates related to strains of Papaya ringspot virus, Phytopathology, v.80, 256-263, 1990.

SÁNCHEZ, M.V.; AGÜERO, R.; IVERA, C. Plantas hospederas de los vírus más importantes que infectan el melón, Cucumis melo (Cucurbitaceae) en Costa Rica. Revista de Biologia Tropical, v.46, n.1, p. 13-25, 1998.

SHATTTUCK-EIDENS, D.M.; BELL, R.N.; NEUHAUSEN, S.L.; HELENTJARIS, T. DNA sequence variation within maize and melon: observations from polymerase chain reaction amplification and direct sequencing. Genetics, v.126, p.207-217, 1990.

SILBERSTEIN, L.; KOVALSKI, I.; HUANG, R.; ANAGNOSTOU, K.; JAHN, M.M.K.; PERL-TREVES, R. Molecular variation in melon (Cucumis melo L.) as revealed by RFLP and RAPD markers. Scientia Horticulturae, v. 79, p. 101-111, 1999.

SMITH, S.; BEAVIS, W. The impact of plant molecular genetics. Boston: Birkhauser. 1996. p. 259-272.

SOWELL, G.; DEMSKI, J.W. Resistance du melon au virus de la mosaique de la pasteque. FAO Bulletin Phyto Sanitaire, v.29, p. 71-73, 1981.

STAUB, J.E., BOX, J., MEGLIC, V., HOREJSI, T.F., McCRIGHT, J.D., Comparison of isozyme and random amplified polymorphic DNA data for determining intraspecif variation in Cucumis. Genetics Research Crop Evolution, v.44, p. 257-269, 1997. 
VAN ECK, H.J.; VAN DER VOORT, J.R.; DRAAISTRA, J.; VAN ZANDVOORT E.; VAN ENCKEVORT. The inheritance and chromosomal localization of AFLP markers in a non-imbred potato offspring, Molecular Breeding, v. 1, p. 397-410, 1995.

VOS, P.; HOGERS, R.; BLEEKER, M.; REIJANS, M.; VAN DE LEE, T.; HORNES, M.; FRIJTERS, A.; POT, J.; PELEMAN, J.; KUIPER, M.; ZABEAU, M. AFLP: a new technique for DNA fingerprinting. Nucleic Acids Research, v.23, n.21, p.4407-4414, 1995.

VUYLSTEKE, M.; MANK, R.; BRUGMANS, B.; STAM, P.; KUIPER, M. Further characterization of AFLP data as a tool in genetic diversity assessments among maize (Zea mays L.) inbred lines. Molecular Breeding, v.6, p. 26$276,2000$.

WANG, Y.H.; THOMAS, C.E.; DEAN, R.A.. A genetic map of melon (Cucumis melo L.) based on amplified fragment lengh polymorphism (AFLP) markers. Theoretical and Applied Genetics, v.95, p. 791-798. 1997.

WANG, Y.H.; THOMAS, C.E.; DEAN, R.A.. Genetic mapping of a fusarium resistance gene (Fom-2) in melon (Cucumis melo L.). Molecular Breeding, v.6, p.379-389, 2000.

WEBB, R. E.. Inheritance of resistance to Watermelon Mosaic Virus 1 in Cucumis melo L. HortScience v.14, n.3, p.265-266, 1979.

WECHTER, W. P., DEAN, R. Development of sequence-specific primers that amplify a 1.5kb DNA marker for race 1 fusarium wilt resistance in Cucumis melo L. HortScience, v. 33, n.2, p.291-292, 1998. 
YOUNG, N.D.; TANKSLEY, S.D. RFLP analysis of the size of chromossomal segments retained around the $\mathrm{Tm}-2$ locus of tomato during backcross breeding. Theoretical and Applied Genetics, v.77, p. 353-39, 1989

YOUNG, N.D.; ZAMIR, D.; GANAL, M.W.; TANKSLEY, S.D. Use of isogenic lines and simultaneous probing to identify DNA markers tightly linked to the Tm-2a gene in tomato. Genetics, v. 120, p. 579-585, 1988.

YUKI, V.A. Epidemiologia e controle do mosaico (VMM-Me) em abobrinhade-moita. Tese, Escola Superior de Agricultura "Luiz de Queiroz", Universidade de São Paulo, Piracicaba, 1990.

YUKI, V.A.; REZENDE, J.A.M.; KITAJIMA, E.W.; BARROSO, P.A.V.; KUNIYUKI, H.; PAVAN, M.A. Occurrence, distribution and relative incidence of five viruses infecting cucurbits in the state of São Paulo, Brasil. Plant Disease, v.84, n.5, p. 516-620, 2000.

ZAMBOLIM, E. M.; DUSI, A. N. Doenças causadas por vírus em cucurbitáceas. Informe Agropecuário, v.17, n.182, p.60-62, 1995.

ZHENG, X. Y.; WOLFF, D. W.; BAUDRACCO-ARNAS, S. Development and utility of cleaved amplified polymorphic sequences (CAPS) and restriction fragment length polymorphism (RFLPs) linked to the Fom-2 fusarium wilt resistance gene in melon (Cucumis melo L.). Theoretical and Applied Genetics. v.99, p.453-463, 1999.

ZITTER, T.A.; HOPKINS, D.L.; THOMAS, C.E.; Compendium of cucurbit diseases. St. Paul: American Phytopathological Society, 1996. 234p. 